\title{
A Dieta Mediterrânica na Prevenção de Cancro
}

\author{
Rodrigo Queiroz de Athayde Pinheira Nemésio ${ }^{1}$ \\ ${ }^{1}$ Faculdade de Medicina da Universidade de Coimbra, Portugal.
}

\begin{abstract}
Resumo
O fenómeno da globalização, a aceleração acentuada do ritmo de vida e a crescente inserção da mulher no mercado de trabalho, entre outros fatores, têm provocado alterações profundas no estilo de vida da Sociedade Moderna. De entre as mudanças não negligenciáveis que ocorreram de forma particular nos países do Sul da Europa, nomeadamente em Portugal, conta-se a modificação dos hábitos alimentares, com o abandono da tradicional "Dieta Mediterrânica", em detrimento de regimes que propiciam o desenvolvimento de patologias como a hipertensão arterial, diabetes e doenças oncológicas. Ao longo deste artigo, procurar-se-á, num primeiro momento, analisar as características deste regime alimentar característico dos países Mediterrânicos, e que é hoje considerado um paradigma de alimentação saudável. Posteriormente, tomando como ponto de partida uma revisão de publicações recentes, expor-se-á a relação existente entre a alimentação e o desenvolvimento de cancro, pondo em evidência a forma como os diferentes tipos de nutrientes vão, por exemplo, influenciar a capacidade de resposta do organismo a estímulos carcinogénicos. Finalmente, proceder-se-á a uma revisão de estudos que analisam de forma pormenorizada as especificidades dos regimes alimentares do Sul da Europa e forma como esta "Dieta Mediterrânica" - no sentido lato do termo - influencia, por exemplo, a prevalência, incidência e morbimortalidade associada à patologia oncológica.
\end{abstract}

Palavras-chave: cancro; dieta mediterrânica; nutrição e cancro; prevenção primária.

\section{Abstract}

The phenomenon of globalization, the hectic and ever-accelerating pace of life, and the increasing number of women entering the work force are factors, among others, which have profoundly altered the lifestyle of the Modern Society. Amongst these hardly negligible changes occurring particularly in Southern Europe, and namely Portugal, is the modification of eating habits, leading people to abandon the traditional "Mediterranean diet" and increasing their likelihood of suffering from a variety of chronic diseases. The present work aims firstly to analyze the characteristics of this Southern European dietary regime, nowadays considered a paradigm of healthy eating habits. Secondly, taking into account a review of recent studies, the focus will be on the relationship established between nutrition and the development of cancer, namely in the different ways in which different nutrients can influence the body's response to carcinogenic stimuli. Lastly, we will present a revision of studies which analyze the specific nature of dietary regimes in southern Europe and the ways in which the "Mediterranean diet," in the broad sense of the word, influence the prevalence, incidence and morbimortality associated to oncological diseases.

Keywords: mediterranean diet; nutrition and cancer; primary prevention

\section{Introdução}

O incontornável papel que a alimentação assume enquanto determinante da Saúde tem atraído cada vez mais a atenção da comunidade científica. Doenças crónicas como o cancro têm-se tornado cada vez mais prevalentes, mesmo em faixas etárias mais jovens. Se por um lado se observa uma profunda transformação dos hábitos de 
consumo das populações, que decorre do recente desenvolvimento económico das sociedades, por outro lado, o perfil genético da Humanidade pouco mudou nos últimos 10.000 anos. Efetivamente, durante milhões de anos de evolução, os nossos antepassados adaptaram-se a dietas pobres em gordura e ricas em hidratos de carbono, baseadas sobretudo no consumo de carne magra, peixe, frutas, vegetais, ovos e frutos secos, que contrastam, francamente, com as novas tendências nutricionais da sociedade industrializada: o aumento do consumo de energia com concomitante diminuição dos gastos energéticos, o incremento de consumo de gorduras saturadas, ácidos gordos ómega $6(\omega-6)$, gordura trans, grãos de cereais e a diminuição de consumo de ácidos gordos ómega 3 ( $\omega$-3), fibra e hidratos de carbono complexos, proteínas, antioxidantes e cálcio. Não será, pois, de estranhar que, nos anos 70 do século $X X$, tenham surgido os primeiros estudos sobre o impacto que a adoção de uma dieta desequilibrada tem no risco de desenvolvimento de doenças crónicas e, simultaneamente, se tenham estudado os padrões dietéticos que, como a Dieta Mediterrânica, se parecem correlacionar com melhores perfis de sobrevida e menor prevalência de doenças crónicas.

\section{A Dieta Mediterrânica e o seu Papel na Promoção da Saúde}

O primeiro estudo de natureza científica que abordou, de forma sistemática, os hábitos alimentares numa região do Mediterrâneo teve lugar na Grécia, em 1948, em pleno período do pós-guerra (II Guerra Mundial). Nesse tempo de particular carência, preocupações relacionadas com as condições económicas, sociais e sanitárias levaram o governo grego a solicitar o apoio de uma fundação norte-americana - a Rockefeller Foundation - para que se levasse a cabo uma análise epidemiológica na Ilha de Creta, com o propósito de determinar a forma ideal de melhorar as condições de vida da população (Nestle, 1995). Coube ao epidemiologista Leland Allbaugh a tarefa de elaborar um relatório detalhado sobre as características alimentares da população local, tendo este investigador publicado uma monografia, em 1953, com 50 páginas de questionários e um apêndice de 75 páginas de métodos estatísticos, analisados criticamente (Allbaugh, 1953). Concluiu-se, nesse estudo, que os hábitos alimentares dos cretenses eram surpreendentemente equilibrados, encontrando-se perfeitamente adaptados aos recursos naturais e económicos locais, bem como às necessidades nutricionais de cada indivíduo. A base da sua dieta consistia, fundamentalmente, e desde há quarenta séculos, em azeitonas, grãos de cereais, leguminosas, vegetais e fruta, complementados com pequenas quantidades de queijo e carne de cabra, carne de caça e peixe, sem nunca esquecer o pão e o vinho. Os produtos de fontes vegetais representavam $61 \%$ da energia obtida através da dieta, os alimentos de origem animal contribuíam com $7 \%$ e os óleos usados nas refeições $29 \%$, maioritariamente através do consumo de azeite (Allbaugh refere mesmo que alguns alimentos vinham, literalmente, a "nadar em azeite" ("swimming in oil") (1953)) (Nestle, 1995). Os dados obtidos relativamente à população da Ilha de Creta foram comparados com resultados homólogos referentes à restante população grega e à população americana (ver tabela 1).

Tabela 1. Contributo de cada grupo alimentar major para o total de energia consumida, através da dieta, nas populações de Creta, da Grécia e dos EUA [adaptado de (Nestle, 1995)]

\begin{tabular}{|c|c|c|c|}
\hline Grupo alimentar & $\begin{array}{c}\text { Creta } \\
\text { (registo de } 7 \text { dias) }\end{array}$ & $\begin{array}{c}\text { Grécia } \\
\text { (balança alimentar) }\end{array}$ & $\begin{array}{c}\text { EUA } \\
\text { (balança alimentar) }\end{array}$ \\
\hline (MJ/dia) & 10,6 & 10,4 & 13,1 \\
\hline (kcal/dia) & 2547 & 2477 & 3129 \\
\hline Cereais & 39 & 61 & 25 \\
\hline $\begin{array}{l}\text { Leguminosas, frutos } \\
\text { secos e batatas }\end{array}$ & 11 & 8 & 6 \\
\hline Fruta e vegetais & 11 & 5 & 6 \\
\hline Carne, peixe, ovos & 4 & 3 & 19 \\
\hline Laticínios & 3 & 4 & 14 \\
\hline Óleos “de mesa” e gorduras & 29 & 15 & 15 \\
\hline Açúcar e mel & 2 & 4 & 15 \\
\hline Vinho, cerveja e bebidas espirituosas & 1 & a & a \\
\hline
\end{tabular}

a - Dados não disponíveis

Apesar de o estudo da Rockefeller Foundation ter concorrido, de forma notável, para a caracterização dos hábitos alimentares dos habitantes da Ilha de Creta, não é senão no final da década de 50 do século XX que surge a primeira 
referência a uma "Dieta Mediterrânica", capaz de conferir proteção contra várias patologias (Allbaugh, 1953). Em 1952, um dietista do Minnesota, Ancel Keys, questionando-se sobre a baixa mortalidade e reduzida incidência de doenças cardiovasculares observadas nas populações do Sul da Itália e em Creta, inicia um projeto de investigação, que se estenderia pelas décadas de 50-60, por forma a tentar elucidar as razões para o excecionalmente bom desempenho cardiovascular dessas populações mediterrânicas. De facto, quando comparados com os EUA e as nações do Norte europeu, os países do Sul da Europa apresentavam uma maior esperança média de vida e mais baixas taxas de patologia coronária, AVC, de doenças metabólicas e de alguns tipos de cancro, principalmente tendo em conta a relativa pobreza e o pior acesso aos cuidados de saúde nessas regiões (Nestle, 1995; Ferrari \& Rapezzi, 2011).

No ano de 1959, é a mulher de Ancel Keys, Margaret Keys, quem reúne uma série de receitas baseadas no conceito de "Dieta Mediterrânica", publicando-as em coautoria com o seu marido e com um prefácio elaborado por um proeminente cardiologista da altura, o Dr. Paul Dudley White, naquele que será, provavelmente, o primeiro livro de receitas (Keys \& Keys, 1959) idealizado em prol de um "coração saudável" (Nestle, 1995). A tabela 2 serve de instrumento comparativo entre as recomendações dietéticas propostas por Keys, neste seu livro de 1959, tendo por base o já referido estudo da Dieta Mediterrânica (Nestle, 1995) e os mais recentes conselhos para uma alimentação saudável publicados pela Direção-Geral da Saúde (DGS) em 2005, que podem ser consultados na sua página da internet (Direção-Geral da Saúde, 2011). Esta comparação permite demonstrar a atualidade das recomendações de Keys e a influência decisiva que o seu trabalho de investigação continua a ter na elaboração das atuais premissas para uma dieta saudável.

Os primeiros dados deste estudo clássico de Keys foram finalmente publicados em 1980 (Keys, Aravanis, Blackburn, Buzina, Djprdjevic, Dontas, et al., 1980). Trata-se do Seven Countries Study, que é, talvez, o primeiro estudo epidemiológico a explorar as associações existentes entre os hábitos alimentares e a incidência e mortalidade por diversas patologias (como doenças cardiovasculares (DCV) e cancro) em diferentes populações, a longo prazo, ou, noutros termos, a analisar as correlações ambientais de doenças crónicas (Blackburn, 2012; Tyrovolas \& Panagiotakos, 2010). O Seven Countries Study consistiu numa análise comparativa de 16 estudos de coorte em 7 países de vários pontos do planeta: um nos EUA, dois na Finlândia, um nos Países Baixos, três em Itália, cinco na antiga Jugoslávia (dois na Croácia e três na Sérvia), dois na Grécia e dois no Japão. Este estudo seguiu, durante 25 anos, 12.763 homens de meia-idade (dos 40 aos 59 anos), reunindo os dados sociodemográficos, clínicos, dietéticos e relativos ao estilo de vida de cada um (Tyrovolas \& Panagiotakos, 2010). Os resultados revelaram uma discrepância significativa entre a prevalência de DCV nos países do Sul da Europa, com taxas de 2 a $10 \%$, e a dos seus homólogos do Norte, que apresentavam valores na ordem dos 10-18\%. As diferenças nas taxas de mortalidade, ajustadas por idades, também eram apreciáveis, tendo-se registado valores 10 vezes superiores nalguns países comparativamente a outros; se, na Finlândia ocidental, por exemplo, esta cifra se situava nos $268 \%$, em Creta esta taxa só atingia os 25\%o (Tyrovolas \& Panagiotakos, 2010).

Os fundamentos para tais disparidades foram atribuídos às divergências entre os hábitos alimentares de cada participante, em particular, no que toca às quantidades de ácidos gordos saturados e flavonóides ingeridos. De facto, constatou-se que o contributo de todo o tipo de gorduras para a energia total consumida pelos indivíduos originários dos diferentes países não sofria grandes flutuações. A principal diferença residia no tipo de gorduras que, maioritariamente, compunham a dieta. Nos países da Europa do Norte, a preferência pela manteiga, pela banha, pelos laticínios, bem como por outros produtos de origem animal determinava um elevado consumo de gorduras saturadas e de colesterol. Por seu turno, nos países do Sul da Europa, dava-se primazia ao azeite enquanto fonte de gordura, rico em ácidos gordos insaturados, além de se verificar, concomitantemente, um elevado consumo de cereais, legumes, hortaliças, peixe e vinho, observando-se, nesses mesmos países, taxas de mortalidade relativamente mais baixas.

Tabela 2. Confronto entre as recomendações dietéticas estabelecidas por Ancel Keys em 1958, no seguimento do seu estudo da Dieta Mediterrânica, e as recomendações para uma alimentação saudável, publicadas pela DGS em 2005.

\begin{tabular}{cc}
\hline Recomendações de Keys (1958)a & Recomendações da DGS (2005)b \\
\hline $\begin{array}{c}\text { Não engordar. Quem tiver excesso de peso deve emagrecer. } \\
\text { Praticar exercício físico e atividades no exterior. }\end{array}$ & Manter um peso adequado à estatura. \\
\hline Restringir o consumo de gorduras saturadas. & $\begin{array}{c}\text { Reduzir o consumo total de gordura, em especial da } \\
\text { gordura saturada, existente, principalmente, em produtos } \\
\text { de origem animal. }\end{array}$ \\
\hline
\end{tabular}


Preferir óleos vegetais a gorduras sólidas, mantendo o consumo de gorduras abaixo dos $30 \%$ das calorias totais da dieta.

Reduzir o consumo de gordura proveniente de carnes de vaca, porco ou borrego, de salsichas, de margarinas e de produtos lácteos.

Preferir vegetais e fruta fresca.

Favorecer o consumo de laticínios magros.

Evitar o consumo de sal e açúcar refinado.

Uma boa dieta não depende de aditivos nem de preparações rebuscadas.

Ser sensato no consumo de álcool e tabaco, bem como na gestão de emoções e da tensão no trabalho. Visitar regularmente o médico e evitar preocupações
Preferir sempre o consumo de azeite em relação a outras gorduras, quer para cozinhar, quer para temperar os pratos.

Consumir, de preferência, peixe e carnes magras (ex: aves ou coelho).

Aumentar o consumo de hortaliças, legumes e fruta.

Consumir leite e derivados com baixo teor de gordura. Preferir os cereais integrais

Diminuir o consumo de sal $(<5 \mathrm{~g} / \mathrm{dia})$. Evitar ingerir açúcar e produtos açucarados.

Preferir métodos de culinária simples, saudáveis e saborosos (ex: estufados, cozidos e grelhados).

No caso de consumir bebidas alcoólicas, fazê-lo com moderação.

Tomar sempre o pequeno-almoço e não estar mais de $3 \mathrm{~h}$ sem comer.

Beber água, em abundância, ao longo do dia

a - Dados colhidos em Nestle M. Mediterranean diets: historical and research overview. The American Journal of Clinical Nutrition. 1995: p. 1313S-1320S.

b - Dados da DGS, 2005 Direção-Geral da Saúde. [Online][cited 2017 Junho 12 https://www.dgs.pt/upload/membro.id/ ficheiros/i008723.pdf]

Partindo da etimologia da palavra "dieta" - do grego Síaıta (díaita), 'estilo de vida' -, a Fundación Dieta Mediterránea $(\mathrm{FDM})^{1}$, sediada em Barcelona, propõe um sentido mais abrangente para a expressão "Dieta Mediterrânica". Entende que, mais do que um padrão alimentar, a Dieta Mediterrânica consiste num conjunto de aptidões, conhecimentos, práticas e tradições que, da paisagem natural até à mesa, incluem as plantações, as colheitas, a pesca, a conservação, o processamento, a preparação e, particularmente, o consumo dos alimentos, sempre simples e variados, consumidos frescos, de acordo com a época, e de forma sustentável, respeitando, assim, o equilíbrio com a Natureza (Fundación Dieta Mediterránea, 2012). Esta associação encara ainda a Dieta Mediterrânica como uma herança cultural de valor inestimável - reconhecida, aliás, pela UNESCO como Património Cultural Imaterial da Humanidade, a 16 de novembro 2010 (UNESCO, 2012) -, transmitida de geração em geração, que foi sendo edificada ao longo de séculos de adaptação às condições ambientais de toda a bacia do Mediterrâneo e enriquecida em virtude da sua localização geográfica, uma posição estratégica para o fomento de trocas comerciais entre as diferentes culturas mediterrânicas. Tal enquadramento permitiu que se acolhessem e incorporassem novos produtos e técnicas, num processo continuamente ativo, desde a Antiguidade, passando pelo tempo da descoberta do Novo Mundo - que trouxe o tomate, a batata, o milho, por exemplo -, até aos dias de hoje, tornando a Dieta Mediterrânica num património evolutivo, dinâmico e vital (Fundación Dieta Mediterránea, 2012). Releve-se, ainda, um outro aspeto que, de tão característico deste "estilo de vida", se embutiu na própria língua de alguns povos latinos. Comer, do latim vulgar comedere, provém do latim clássico edere - com origem, por sua vez, na raiz indoeuropeia *ed- (presente ainda em outras formas derivadas do latim, como obeso, e que, no inglês, se transforma em eat e, no alemão, em essen, por exemplo) -, ao qual, mais tarde, se junta o prefixo com-, derivado de cum ('com') (Machado 1995; Neto 1947). Na sua essência, então, a própria palavra comer subentende, quase pleonasticamente, comer com, ou seja, um ritual de convívio e partilha e um apelo à hospitalidade e espírito de entreajuda, muito próprios dos povos mediterrânicos.

Quanto à definição da Dieta Mediterrânica na sua vertente gastronómica e nutricional, vale a pena começar por transcrever as palavras de Ferrari e Rapezzi (2011) (Ferrari e Rapezzi 2011), que abordam esta questão de uma forma particularmente interessante:

\footnotetext{
${ }^{1}$ http://dietamediterranea.com/

2 Refira-se, no entanto, que, no latim vulgar, o prefixo cum pode também adquirir valor de intensidade- 'comer tudo', 'devorar' de forma a reforçar as formas simples, semanticamente já desgastadas pelo uso.
} 
From a culinary point of view, the word Mediterranean is as vague as the Mediterranean Sea, bordered by more than 20 countries, each with its own culinary identity. Food is a key component of the identity of a nation, region, family, or an individual. Thus pizza and spaghetti are associated with Italy; cheese and pâté with France; hummus with Magreb; meze with Lebanon; tagine and pastilla with Morocco; paella with Spain; bacalau with Portugal, and so on. So, what is the Mediterranean diet? Is it pizza, tagine, or paella? Actually, it is none and all of these at the same time. This is because the diet refers to ingredients rather than to the actual preparation, and between all of the ingredients it is the olive and olive oil which provides the true identity of the Mediterranean diet. $^{3}$ (Ferrari \& Rapezzi, 2011)

Entende-se, então, que é extremamente difícil, senão impossível, definir um regime alimentar que seja o paradigma da "Dieta Mediterrânica" (Cordova \& Sumpio, 2012). Genericamente, e em virtude deste papel unificador da azeitona e do azeite referidos por Ferrari e Rapezzi, aplica-se o termo "Dieta Mediterrânica" aos padrões alimentares das regiões do Mediterrâneo onde o cultivo de oliveiras se verifica há pelo menos 30 anos (Willet, Sacks, Trichopoulou, Drescher, Ferro-Luzzi, Helsing, et al., 1995). Aceita-se, então, que dentro de um esquema-padrão comum, haja, necessariamente, algumas nuances que variam de país para país, de região para região, mesmo de localidade para localidade, e que deixam impressa, também na dieta, a tradição e cultura próprias de cada área deste Mediterrâneo plural.

Em colaboração com outras entidades, a Fundación Dieta Mediterránea desenvolveu uma pirâmide alimentar que pretende refletir as características da deste padrão alimentar, indicando o tipo de alimentos que o compõem e a periodicidade com que devem ser consumidos (figura 1) (Fundación Dieta Mediterránea, 2012a; Fundación Dieta Mediterránea, 2012b).

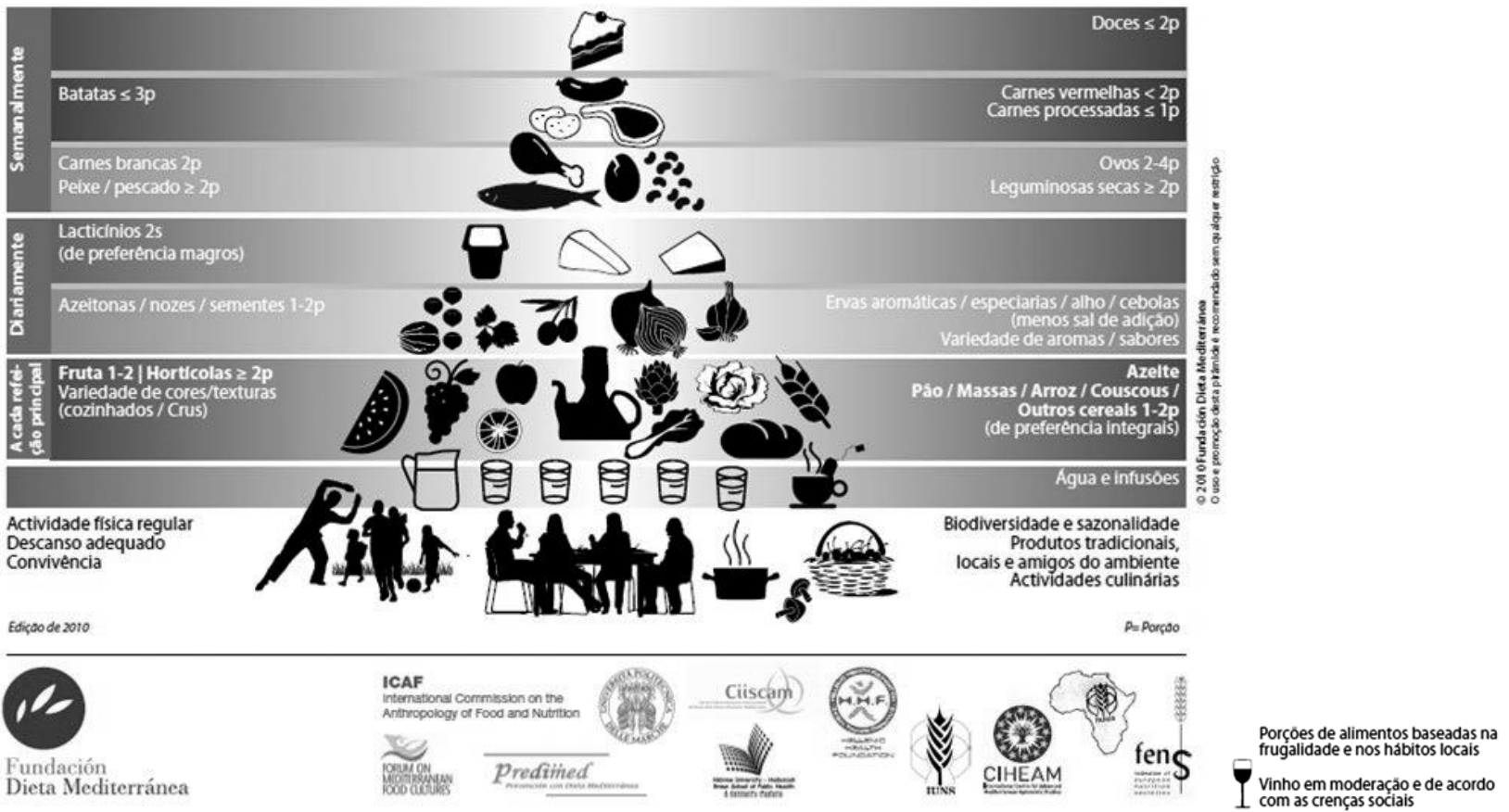

Figura 1. "A Pirâmide da Dieta Mediterrânica: um estilo de vida para os dias de hoje - recomendações para a população adulta" (Fundación Dieta Mediterránea, 2012b)

\footnotetext{
3 “De um ponto de vista gastronómico, a palavra mediterrânico é tão vaga quanto o Mar Mediterrâneo, que banha mais de 20 países, cada um com a sua própria identidade culinária. A alimentação é um componente-chave da identidade de uma nação, região, família ou indivíduo. Assim, a pizza e o esparguete são associados à Itália; o queijo e o patê à França; o hummus ao Magreb; o meze ao Líbano; a tajine e a pastilla a Marrocos; a paelha a Espanha; o bacalhau a Portugal, e por aí adiante. Então, o que é a Dieta Mediterrânica? É pizza, tajine ou paelha? Na verdade, não é nenhum e são todos eles ao mesmo tempo. E isto, porque a dieta diz respeito a ingredientes, mais do que ao modo como são preparados, e, de entre todos os ingredientes, são a azeitona e o azeite que conferem a verdadeira identidade à Dieta Mediterrânica." (tradução da responsabilidade do autor).
} 
Antes, porém, de se iniciar a análise mais detalhada dos componentes da Dieta Mediterrânica, vale a pena mencionar um aspeto não desprezível de um estudo conduzido por Trichopoulou et al. (2003) (Trichopoulou, Costacou, Bamia \& Trichopoulos, 2003). Se este trabalho de investigação confirmou que, de facto, a adesão à Dieta Mediterrânica está associada a menores taxas de mortalidade e a números mais baixos de morte cardiovascular, com benefícios significativos para indivíduos com 55 e mais anos de idade, não se observaram correlações significativas entre estes parâmetros e cada um dos componentes da dieta, encarados isoladamente (Chahound, Aude \& Mehta, 2004). Sabe-se mesmo que nem todos os elementos do regime alimentar são necessariamente protetores, e os que o são não conferem todos o mesmo grau de proteção (Panagiotakos, Pitsavos \& Stefanadis, 2006). Deve, então, reconhecer-se que, ao fazer o inventário de cada elemento da Dieta Mediterrânica isoladamente, numa tentativa de avaliar o seu contributo para a proteção contra doenças crónicas, está a incorrerse numa falácia, pelo facto de os extirparmos da sua interação com todos os outros componentes. Ainda assim, esta afigura-se, talvez, como a melhor forma de, neste trabalho, proceder à sua exposição por escrito.

\subsection{Produtos de Origem Vegetal: Fruta, Hortícolas e Cereais}

Este grupo de alimentos constitui o cerne da Dieta Mediterrânica tradicional, não podendo faltar em nenhuma refeição principal. Com origem em civilizações agrícolas, os povos do Mediterrâneo habituaram-se a produzir o seu próprio alimento - cultivam o que necessitam e aprendem a processar os alimentos ${ }^{4}-$, evitando tornar-se reféns da caça e da exploração das florestas, como acontecia com os povos nómadas do Norte, o que também ajuda a explicar o reduzido contributo de produtos de origem animal na Dieta Mediterrânica (Ferrari \& Rapezzi, 2011). Vegetais secos, saladas, fruta e frutos secos, sementes e azeitonas, bem como a utilização de alho e cebolas como condimentos e ervas aromáticas em substituição de algum sal, constituem complementos fundamentais de qualquer refeição da Dieta Mediterrânica (Willet, Sacks, Trichopoulou, Drescher, Ferro-Luzzi, Helsing, et al., 1995). Mas também muitos pratos principais tradicionais, servidos em vários pontos do Mediterrâneo, têm por base alimentos de origem vegetal: cuscuz, vegetais e legumes no Norte de África; massa, polenta, arroz e batatas, com vegetais e legumes, no Sul da Europa; bulgur e arroz, com vegetais, grão-de-bico e feijão, nas regiões do Mediterrâneo Oriental (Willet, Sacks, Trichopoulou, Drescher, Ferro-Luzzi, Helsing, et al., 1995).

Os verões secos e os invernos temperados da região mediterrânica proporcionam um período ótimo para o cultivo de vegetais e frutos, um lapso de tempo mais alargado do que o que se pode obter noutras latitudes. Acrescente-se, ainda, a este propósito, que os longos períodos de exposição solar induziram, na vegetação local, um mecanismo de defesa natural contra as espécies reativas de oxigénio, geradas durante a fotossíntese. Este processo já foi correlacionado com a abundância de antioxidantes existentes na flora mediterrânica (Huang \& Sumpio, 2008).

O elevado consumo de fruta e vegetais, ricos em fibra, tal como indiciam vários estudos, é protetor contra algumas formas de cancro, doença coronária, defeitos do tubo neural e cataratas. Os vegetais são, na Dieta Mediterrânica, a mais importante fonte de compostos fenólicos, bons agentes antioxidantes, particularmente de flavonóides. São ainda uma importante fonte de fitoesteróis, úteis na redução dos níveis de colesterol plasmático e na prevenção de DCV. Além de ricas em fibra, vitaminas, minerais, flavonóides, carotenóides e terpenos, muitos dos quais com uma função antioxidante essencial, as frutas, bem como alguns vegetais, legumes e cereais integrais, são ricas em fitoestrogénios que, no intestino, são convertidos em estrogénios que podem, por exemplo, contribuir para a contrabalançar os efeitos da privação hormonal durante a menopausa. O uso, na Dieta Mediterrânica, do alho, da cebola e de ervas aromáticas e especiarias também se relaciona com um aumento do valor nutricional dos alimentos. Alguns destes condimentos contêm, igualmente, grandes quantidades de flavonóides (como o funcho e o cebolinho) ou de alicina (como o alho cru e a cebola), que trazem benefícios cardiovasculares e aumentam o nível do desempenho cognitivo. Também as alcaparras, muito utilizadas em saladas e pizzas, oferecem múltiplas vantagens medicinais, com efeito diurético, anti-hipertensivo, anti-inflamatório, antioxidante e condroprotetor, além de auxiliarem no controlo da peroxidação lipídica. Já os frutos secos são particularmente ricos em compostos fenólicos,

\footnotetext{
${ }^{4} \mathrm{O}$ exemplo mais flagrante deste tipo de alimentos será o pão, que é considerado o mais marcante símbolo da Agricultura e da Civilização Humana, e que constitui um componente fundamental em praticamente todas as refeições de uma Dieta Mediterrânica típica, consumido simples, sem adição de manteiga ou margarina (Willet, Sacks, Trichopoulou, Drescher, FerroLuzzi, Helsing, et al., 1995).
} 
flavonóides, isoflavonóides, fitoesteróis e ácido fítico, e estão associados à diminuição dos lípidos plasmáticos, com efeito protetor contra DCV. (Graça, 2012)

\subsection{Azeite}

O azeite, que constitui, como já se salientou, a principal fonte de gordura da Dieta Mediterrânica, é extraído da azeitona - um fruto -, fundamentalmente através de um simples processo físico de pressão (Galli, Marangoni, 2006). Usado em vez da manteiga e de outras gorduras de origem animal, comuns no Norte da Europa, o azeite tem uma elevada proporção de ácidos gordos monoinsaturados e baixos níveis de ácidos gordos saturados, constituindo, adicionalmente, uma boa fonte de vitamina E, um antioxidante lipossolúvel (Willet, Sacks, Trichopoulou, Drescher, Ferro-Luzzi, Helsing, et al., 1995). Mais de $98 \%$ do peso do azeite é constituído por gliceróis, dos quais a grande maioria são triacilgliceróis. Por sua vez, o ácido gordo com maior representatividade nos triacilgliceróis é o ácido oleico (70-80\%), que é monoinsaturado. Os restantes $2 \%$ dos componentes do azeite são um conjunto de mais de 230 substâncias químicas - e, de entre estas, diversos fitoquímicos, como compostos polifenólicos, esqualeno e $\alpha$ tocoferol (4) -, muitas das quais com importantes efeitos cardiovasculares, que, no entanto, são perdidos durante $o$ processo de refinação do azeite virgem e extravirgem (o mais puro) (Huang \& Sumpio, 2008).

Quando comparado com outras gorduras alimentares, o azeite demonstrou apresentar um conjunto de vantagens para a saúde: (i) o ácido oleico é considerado antitrombótico em comparação com ácidos gordos saturados; (ii) dietas ricas em gorduras polinsaturadas têm maior probabilidade de se encontrarem envolvidas nos processos de oxidação das LDL - que elevam o risco de aterogénese e de doença coronária - do que dietas ricas em gorduras monoinsaturadas; (iii) demonstrou-se, já, que a substituição de alguns hidratos de carbono da dieta por azeite aumenta a concentração de HDL, sem que os níveis de LDL se alterem, com consequente diminuição do risco de DCV; (iv) a utilização do azeite na dieta já foi testada pelos povos mediterrânicos ao longo de milénios, sem que se verificassem graves prejuízos para a saúde, mas ainda não são conhecidas as implicações médicas, a longo prazo, do recurso a óleos vegetais polinsaturados, recentemente introduzidos no mercado; (v) o azeite facilita o consumo de grandes quantidades de vegetais e legumes, uma vez que intensifica o seu sabor e Ihes confere maior densidade energética (Willet, Sacks, Trichopoulou, Drescher, Ferro-Luzzi, Helsing, et al., 1995).

Além da redução do risco de DCV através da melhoria dos perfis lipídicos (diminuição do colesterol total e de LDL e aumento de $\mathrm{HDL}$ ), diminuição da oxidação de LDL, inibição da agregação plaquetar e promoção da fibrinólise (Cordova \& Sumpio, 2012; Willet, Sacks, Trichopoulou, Drescher, Ferro-Luzzi, Helsing, et al., 1995; Huang \& Sumpio, 2008), há ainda estudos (Graça, 2012) que indiciam que o consumo de azeite está relacionado com a prevenção de alguns tipos de cancro, com uma melhoria do sistema imunitário e com a promoção da mineralização óssea, reduzindo o risco de osteoporose.

\subsection{Laticínios}

A Dieta Mediterrânica integra, tradicionalmente, quantidades pequenas a moderadas de leite e derivados, com origem em diferentes animais: cabra, ovelha, vaca, búfalo e camelo. O clima quente e a inexistência de técnicas de refrigeração não permitiam, noutros tempos, que o leite se conservasse fresco durante muito tempo, pelo que se dava preferência ao consumo de queijo e iogurtes, muitas vezes incorporados, em pequenas porções, em pratos de massa ou em saladas, por exemplo. A recente introdução de laticínios magros no mercado permitiu que se admitisse o consumo destes produtos em maiores quantidades, sem que daí advenha um aumento do risco para a saúde, apesar de tal ainda não ter sido absolutamente comprovado (Willet, Sacks, Trichopoulou, Drescher, Ferro-Luzzi, Helsing, et al., 1995; Huang \& Sumpio, 2008).

Além de serem mais bem tolerados por indivíduos intolerantes à lactose, o queijo e o iogurte trazem benefícios probióticos, quer a nível gastrointestinal, quer no que toca à resposta imunitária, em virtude das bactérias ácidoláticas usadas na fermentação do leite. O consumo de iogurte poderá, ainda, induzir alterações favoráveis da flora intestinal, atenuar os efeitos de alguns fatores de risco para cancro do cólon e ainda ajudar a regular o trânsito digestivo, da boca ao cego (Graça, 2012). 


\subsection{Carne, Peixe, Ovos}

Seguindo os padrões da Dieta Mediterrânicas, o consumo de carne é muito limitado, particularmente quando comparado com as chamadas "dietas ocidentalizadas", em que este tem um contributo mais significativo. Essa ingestão exacerbada de carne de vaca, porco, borrego, etc. está comprovadamente correlacionada com uma maior incidência de doenças crónicas, como DCV e patologias do foro oncológico. Foram identificados vários fatores que contribuem para este papel nocivo da carne - e, particularmente da carne vermelha - para a saúde: (i) o elevado teor de gorduras, nomeadamente de colesterol; (ii) a proteína e o ferro que contém em grandes quantidades; (iii) a ausência de fibra; (iv) a baixa concentração em compostos antioxidantes; (v) as substâncias carcinogénicas formadas durante o processo da sua fritura ou assadura ${ }^{5}$. O consumo moderado de carnes brancas e a ingestão extremamente reduzida de carnes vermelhas associados à Dieta Mediterrânica não demonstra qualquer risco para a saúde e está associado a melhores perfis de saúde do que os que se observam entre populações acostumadas à ingestão grandes quantidades de carne (Willet, Sacks, Trichopoulou, Drescher, Ferro-Luzzi, Helsing, et al., 1995; Huang \& Sumpio, 2008).

O consumo de peixe é bastante inconstante no seio dos países mediterrânicos, sendo mínimo em Creta (Grécia) e no Sul de Itália e máximo em Corfu (Grécia), Espanha e Portugal (Willet, Sacks, Trichopoulou, Drescher, Ferro-Luzzi, Helsing, et al., 1995; Huang \& Sumpio, 2008). Os peixes - e, particularmente, os peixes gordos, como a sardinha, a cavala, as anchovas e o atum - são ricos em ácidos gordos $\omega$-3 (ácidos gordos essenciais, como o ácido eicosapentaenóico e o ácido docosahexaenóico), que desempenham um papel importante na regulação dos fatores hemostáticos, diminuem a incidência de arritmias, hipertensão e doenças oncológicas, auxiliam na manutenção das funções neurais e previnem o surgimento de alguns distúrbios psiquiátricos (Graça, 2012). O consumo de quantidades baixas a moderadas de peixe por semana está, comprovadamente, relacionado com níveis de saúde excelentes (Willet, Sacks, Trichopoulou, Drescher, Ferro-Luzzi, Helsing, et al., 1995; Huang \& Sumpio, 2008); um estudo prospetivo de Albert et al. (1998) (Albert, Hennekens, O’Donnell, Ajani, Carey, Willet, et al., 1998) chegou mesmo a revelar que o consumo de pelo menos um peixe por semana está diretamente relacionado com uma diminuição do risco de morte súbita cardíaca em homens. No consumo de peixe, em particular, Portugal terá uma vantagem em relação aos outros países da região mediterrânica, facto que não se prende apenas com o maior consumo deste componente da dieta: o peixe de águas mais frias, como as do Oceano Atlântico, que banha Portugal, tende a dispor de uma maior concentração de ácidos gordos $\omega-3$ do que o peixe das águas mais temperadas do Mar Mediterrâneo (Galli \& Marangoni, 2006).

Já no que respeita ao consumo de ovos, seguindo uma Dieta Mediterrânica tradicional, como a verificada no início da década de 1960, este situava-se entre as zero e as quatro unidades per capita por semana (Willet, 1999).

\subsection{Vinho}

Muitas culturas mediterrânicas - e, aqui, devem excluir-se as de religião muçulmana - têm por hábito o consumo de vinho durante as refeições, de forma moderada (definida por um máximo de 1-2 copos por dia para os homens) (Willet, Sacks, Trichopoulou, Drescher, Ferro-Luzzi, Helsing, et al., 1995). O vinho, além de água, etanol, glicerol e açúcar, contém centenas de outras substâncias, incluindo uma elevada concentração de polifenóis - especialmente o vinho tinto, uma vez que estes compostos derivam das cascas e grainhas das uvas, que constituem os principais conservantes do vinho tinto durante a fermentação ${ }^{6}$-, poderosos agentes antioxidantes, que reduzem os níveis de radicais livres, poupam a vitamina $\mathrm{E}$ e os carotenóides presentes nas partículas de LDL, preservando o seu efeito antioxidante. Aumentam, ainda, a atividade da paraoxonase, uma enzima presente no soro, que promove a hidrólise de peróxidos lipídicos nas células arteriais e nas LDL (Cordova \& Sumpio, 2012). Estes polifenóis trazem ainda outros efeitos benéficos para a saúde, como a alteração dos perfis lipídicos e das cascatas de coagulação e fibrinólise, a inibição da agregação plaquetar e a modelação da função endotelial, favorecendo a vasodilatação (Graça, 2012). Um destes

\footnotetext{
${ }^{5}$ Note-se, ainda, que os Romanos, ao contrário dos povos "bárbaros" do Norte, usavam processos de confeção indiretos para cozinhar a carne, como a cozedura, que liberta menos carcinogéneos do que a preparação em contacto direto com a chama (Ferrari \& Rapezzi, 2011).

${ }^{6}$ Uma garrafa de vinho tinto contém, em média, 1,8 g/L de polifenóis, ao passo que uma garrafa de vinho branco contém apenas cerca de 0,3 g/L (Cordova e Sumpio 2012).
} 
compostos fenólicos, particularmente abundante no vinho tinto, o resveratrol, demonstrou ter um efeito cardio e renoprotetor, graças ao seu poder antioxidante e ao facto de estimular a síntese de óxido nítrico (Graça, 2012).

O próprio álcool, em quantidades moderadas, traz, comprovadamente, alguns efeitos salutares (Léger-Guist'hau, 2011): (i) aumenta os níveis de HDL e diminui a concentração de LDL no plasma; (ii) inibe a agregação plaquetar; (iii) diminui os níveis de fibrinogénio; (iv) diminui a atividade da metaloproteinase 2 da matriz, envolvida no processo de aterosclerose (Cordova \& Sumpio, 2012). Contudo, nunca será de mais frisar que estes efeitos positivos apenas se verificam para níveis moderados de consumo de álcool - isto é, se não se ultrapassar o consumo de uma ou duas bebidas por dia. Este ponto é ilustrado nos gráficos $1 \mathrm{~A}$ e $1 \mathrm{~B}$, que representam a influência do consumo de álcool no risco relativo de mortalidade por todas as causas ou por DCV, respetivamente, apresentando, distintamente, uma curva em forma de ' $\mathrm{J}$ ' ou de 'U'.
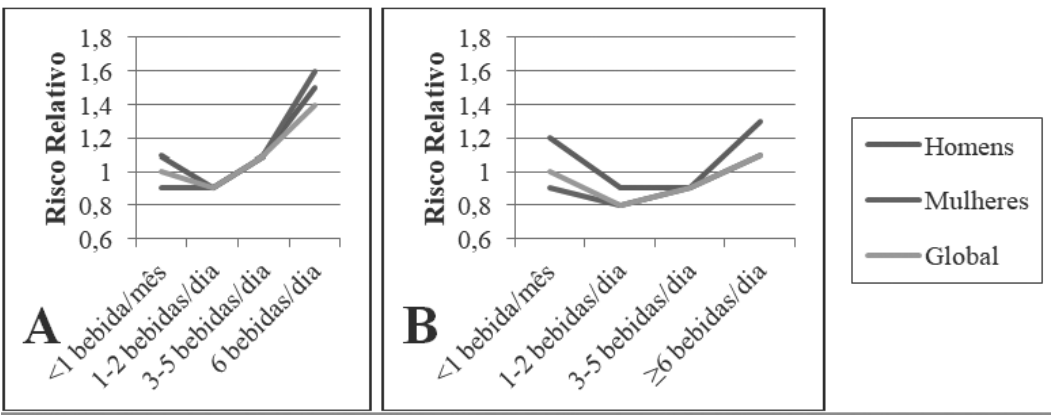

Figura 2. Influência do consumo de álcool no risco relativo de mortalidade por: A - todas as causas; B - DCV [adaptado de (Cordova e Sumpio 2012)].

\subsection{Atividade Física e Estilo de Vida}

Outra característica - detetada nos anos 60, e considerada como definidora da cultura dos povos mediterrânicos - que contribuiu, indubitavelmente, para a elevada esperança média de vida e baixas taxas de morte cardiovascular na região, tem a ver com a prática comum de exercício físico, relacionada não só com a atividade profissional, mas também com as atividades de lazer praticadas ao ar livre e facilitadas pelas excelentes condições climáticas de que a região goza (Graça, 2012; Fundación Dieta Mediterránea, 2012c; Willet, Sacks, Trichopoulou, Drescher, Ferro-Luzzi, Helsing, et al., 1995). Além do hábito da prática de exercício físico regular, Willett et al. (Willet, Sacks, Trichopoulou, Drescher, Ferro-Luzzi, Helsing, et al., 1995) enumeram outros aspetos relacionados com o estilo de vida dos povos do Mediterrâneo que poderão, ainda, ter alguma ligação com os níveis de saúde verificados na região: (i) os apoios sociais e o "sentido de comunidade", que transparecem, aliás, no costume de partilha das refeições com a família e amigos; (ii) refeições demoradas (próximo da ideia de slow food (Slow Food, 2012), uma tendência que se encontra em pleno contraste com o conceito de fast food) que facultam relaxamento e alívio do stresse diário; (iii) receitas culinárias extremamente apelativas ao paladar, preparadas cuidadosamente, que estimulam o gosto por dietas saudáveis; (iv) sestas após o almoço, durante a tarde, que proporcionam um novo momento de repouso e de relaxamento.

A influência da Dieta Mediterrânica na saúde é, habitualmente, avaliada através da aplicação de "escalas de Dieta Mediterrânica" que estimam o grau de aproximação dos hábitos alimentares cultivados pelos participantes nos estudos centrados no regime dietético tradicional dos países mediterrânicos. Para tal, é definida uma série de elementos da dieta, graduados de acordo com a sua ingestão diária, atribuindo-se valor máximo à quantidade que mais se aproxima da Dieta Mediterrânica e "zero" para quantidades mais díspares. Não existe uma escala standard para efetuar esta avaliação, registando-se variações entre as escalas aplicadas por diferentes investigadores. A tabela 3 apresenta, a título de exemplo, a escala sugerida por Panagiotakos et al. (2006) (Panagiotakos, Pitsavos \& Stefanadis, 2006).

Tabela 3. Escala de Dieta Mediterrânica [adaptada de (Panagiotakos, Pitsavos \& Stefanadis, 2006)]

\begin{tabular}{|c|c|c|c|c|c|c|}
\hline & \multicolumn{6}{|c|}{ Frequência de consumo (doses/mês) } \\
\hline & Nunca & $1-4$ & $5-8$ & $9-12$ & $13-18$ & $>18$ \\
\hline Cereais não-refinados (pão integral, massa arroz, etc.) & 0 & 1 & 2 & 3 & 4 & 5 \\
\hline Batatas & 0 & 1 & 2 & 3 & 4 & 5 \\
\hline
\end{tabular}




\begin{tabular}{|c|c|c|c|c|c|c|}
\hline Frutos & 0 & 1 & 2 & 3 & 4 & 5 \\
\hline Vegetais & 0 & 1 & 2 & 3 & 4 & 5 \\
\hline Legumes & 0 & 1 & 2 & 3 & 4 & 5 \\
\hline Peixe & 0 & 1 & 2 & 3 & 4 & 5 \\
\hline Carnes vermelhas & 0 & 4 & 3 & 2 & 1 & 0 \\
\hline Carnes brancas & 0 & 4 & 3 & 2 & 1 & 0 \\
\hline \multirow[t]{2}{*}{$\begin{array}{l}\text { Utilização de azeite na confeção de alimentos } \\
\text { (no de vezes/semana) }\end{array}$} & Nunca & Raro & $<1$ & $1-3$ & $3-5$ & Diariamente \\
\hline & 0 & 1 & 2 & 3 & 4 & 5 \\
\hline \multirow[t]{2}{*}{ Bebidas alcoólicas (ml/dia; $100 \mathrm{ml}=12 \mathrm{~g}$ de etanol) } & $<300$ & 300 & 400 & 500 & 600 & $>700$ ou 0 \\
\hline & 5 & 4 & 3 & 2 & 1 & 0 \\
\hline
\end{tabular}

Diversos investigadores têm aplicado este tipo de escalas para avaliar, por exemplo, o impacto geral da Dieta Mediterrânica na esperança média de vida das populações, apesar da dificuldade em construir instrumentos de avaliação desteitem. Trichoupoulou et al. (1995) reportou uma associação entre o incremento de 1 ponto na escala de Dieta Mediterrânica com uma redução de 17\% na mortalidade global; Knoops et al. (2004) referem uma taxa de mortalidade mais baixa em $23 \%$, entre os indivíduos que obtiveram uma pontuação igual ou superior a 4 numa escala semelhante; o estudo EPIC (European Prospective Investigation into Cancer and Nutrition) Elderly (em idosos) demonstrou a existência de uma relação positiva entre uma maior adesão a parâmetros compatíveis com o padrão da Dieta Mediterrânica e uma maior esperança média de vida, evidenciando que homens com mais de 60 anos que tenham uma pontuação entre 6 e 9 - numa escala de Dieta Mediterrânica de 0 a 10 - viverão, em média, 1 ano a mais, comparativamente a homens na mesma situação, mas que não sigam este tipo de regime alimentar (Simopoulos, 2001).

No entanto, contrariamente ao que seria desejável, a industrialização da sociedade e o fenómeno da globalização têm vindo a provocar um desvio dos padrões da Dieta Mediterrânica nos países em que esta era tradicional, tal como comprovam alguns estudos populacionais levados a cabo nesses países (Kontogianni, Vidra, Farmaki, Koinaki, Belogianni, Sofrona, et al., 2008; Garaulet, Pérez-Llamas, Rueda \& Zamora, 1998; Durão, Oliveira \& Almeida, 2008). Apesar de as autoridades de Saúde e os próprios media terem vindo a alertar para os perigos de uma alimentação desequilibrada e de, nos últimos anos, ter sido desencadeado um esforço para a publicitação da Dieta Mediterrânica e dos seus benefícios, importa que se continue a apostar na responsabilização de cada indivíduo pelas suas escolhas dietéticas e persuadi-los a "retornar às origens", apostar nos produtos locais e sazonais, provenientes de cadeias curtas de distribuição, para assegurar a sua frescura - mas, obviamente, uma aposta sempre adaptada aos tempos atuais.

\section{Nutrição e Cancro}

Uma vasta maioria dos estudos epidemiológicos realizados na área da nutrição e do cancro corroboram a conceção de que um consumo elevado de frutas e vegetais confere proteção contra o desenvolvimento de doenças oncológicas, nomeadamente cancro da boca e faringe, do esófago, pulmão, estômago e reto (Greenwald, Clifford \& Milner, 2001). De igual forma, crê-se que vegetais crucíferos, como os brócolos e a couve-flor, têm um impacto positivo no risco de cancros prostáticos agressivos (Kirsh, Peters, Mayne, Subar, Chatterjee, Johnson, et al., 2007). Todavia, esta conviç̧ão não é consensual na comunidade científica, uma vez que estão disponíveis outros estudos em que a existência de qualquer associação inversa entre o risco de cancro e o consumo de fruta e vegetais não se comprova. Uma análise prospetiva respeitante ao consumo destes alimentos e ao seu efeito na incidência de cancro colorretal (Michels, Giovannucci, Joshipura, Rosner, Stampfer, Fuchs, et al., 2000), por exemplo, não legitimou esta ideia. No caso específico do cancro da mama, e apesar de múltiplos estudos não revelarem a existência de uma relação direta entre a sua incidência e o consumo de vegetais, uma publicação de Michels et al. (2007), por exemplo, depõe em favor da presença de uma relação inversa entre estes dois parâmetros.

Os nutrientes abundantes nos elementos deste grupo alimentar que mais contribuem para o seu papel protetor contra doenças oncológicas são (i) as fibras - particularmente para o cancro da mama e do cólon -, (ii) os micronutrientes e os (iii) fitoquímicos (Greenwald, Clifford \& Milner, 2001). O consumo de grandes quantidades de cereais integrais, particularmente ricos em fibras, demonstrou estar associado a um menor risco de cancro em várias localizações, como sejam, o trato digestivo superior $(0,2-0,3) 7$, o aparelho respiratório $(0,2-0,3)$, o estômago $(0,5)$, o 
cólon $(0,5)$, a vesícula $(0,5)$, o reto $(0,5)$, o fígado $(0,6)$, o pâncreas $(0,8)$, a próstata $(0,8)$, a mama $(0,9)$, o endométrio $(0,9)$, o ovário $(0,6)$, a bexiga $(0,4)$, o rim $(0,4)$, revelando-se, ainda, protetor no caso de linfomas $(0,5)$ e de mielomas $(0,5)$ (Vecchia 2004). Dos micronutrientes destacam-se alguns antioxidantes, como o B-caroteno - que comprovadamente reduz o risco de cancro do pulmão (Greenwald, Clifford \& Milner, 2001) -, a vitamina E implicada na proteção contra cancro do pulmão e do colo do útero (Péres-López, Chedraui, Haya \& Cuandros, 2009) e, eventualmente, contra o cancro da próstata (Ferrís-Tortajada, Berbel-Tornero, García-Castell, Ortega-García, López-Andreu, 2012) e da mama, em mulheres pós-menopáusicas (Michels, Mohllajee, Roset-Bahmanyar, Beehler \& Moysich, 2007) -, a vitamina C - importante na prevenção de cancro do estômago e, possivelmente, de cancros orofaríngeo, esofágico, pulmonar, pancreático e do colo do útero (Greenwald, Clifford \& Milner, 2001) - e o selénio - que reduz o risco de cancro do pulmão e, com alguma probabilidade, de cancro da próstata, de cancros da pele (não-melanoma), de cancro esofágico e do cárdia e de cancro colorretal (Greenwald, Clifford \& Milner, 2001). Ainda no contexto do grupo dos micronutrientes, valerá a pena referir o cálcio e a vitamina $D$, que terão algum papel na prevenção de cancro prostático e colorretal (Gross, 2005), bem como o folato e a metionina (Greenwald, Clifford \& Milner, 2001).

Fitoquímicos são nutrientes que se encontram em alimentos de origem vegetal - produtos hortícolas, frutos e cereais integrais - de composição química diversa, e cujo impacto na redução da incidência de cancro tem sido abordado pela comunidade científica. São inúmeros e complexos os mecanismos através dos quais estes elementos influenciam o processo de oncogénese. A síntese que figura na tabela 4, adaptada de (Greenwald, Clifford \& Milner, 2001), apresenta exemplos de fitoquímicos que influenciam as taxas de incidência de algumas doenças oncológicas.

Tabela 4. Fitoquímicos associados à prevenção do cancro, alimentos nos quais são abundantes e tipos de cancro, por localização, que previnem [adaptado de (Greenwald, Clifford \& Milner, 2001)]

\begin{tabular}{|c|c|c|c|}
\hline $\begin{array}{c}\text { Classe de } \\
\text { fitoquímicos }\end{array}$ & Componentes típicos & $\begin{array}{c}\text { Alimentos nos quais são } \\
\text { abundantes }\end{array}$ & $\begin{array}{l}\text { Exemplos de cancros que, } \\
\text { provavelmente, previnem }\end{array}$ \\
\hline Carotenóides & $\begin{array}{c}\alpha \text {-caroteno, B-caroteno, } \\
\text { licopeno, B-criptoxantina, } \\
\text { luteína, astaxantina }\end{array}$ & $\begin{array}{l}\text { Frutos e vegetais amarelos, } \\
\text { vermelhos ou verdes-escuros }\end{array}$ & $\begin{array}{c}\text { Pulmão; } \\
\text { Próstata, pulmão e } \\
\text { estômago (licopeno) }\end{array}$ \\
\hline $\begin{array}{c}\text { Compostos } \\
\text { organossulfurad } \\
\text { os } \\
\end{array}$ & $\begin{array}{l}\text { Dialil sulfeto, dialil } \\
\text { dissulfeto, alil metil } \\
\text { trissulfeto, ditioltiona }\end{array}$ & $\begin{array}{l}\text { Sulfetos: vegetais alliuma; } \\
\text { ditiolona: vegetais } \\
\text { crucíferosb }\end{array}$ & $\begin{array}{l}\text { Estômago, colorretal } \\
\text { (vegetais allium) }\end{array}$ \\
\hline Polifenóis & $\begin{array}{c}\text { Ácido fenólico, ácido } \\
\text { hidroxicinâmico, flavonóides, } \\
\text { flavononas, catecinas, } \\
\text { teaflavinas, resveratrol }\end{array}$ & $\begin{array}{l}\text { Frutos e vegetais; catecinas: } \\
\text { chá verde; teaflavinas: chá } \\
\text { preto; resveratrol: vinho } \\
\text { tinto }\end{array}$ & $\begin{array}{l}\text { Cancros do trato digestivo } \\
\text { (chá) }\end{array}$ \\
\hline Fitoestrogénios & Isoflavonas, lignanos & $\begin{array}{l}\text { Isoflavonas: soja; lignanos: } \\
\text { vegetais, centeio, semente } \\
\text { de linho }\end{array}$ & $\begin{array}{l}\text { Mama, endométrio, } \\
\text { próstata (soja) }\end{array}$ \\
\hline $\begin{array}{l}\text { Glucosinolatos, } \\
\text { isotiocianatos, } \\
\text { indóis }\end{array}$ & $\begin{array}{l}\text { Glucobrassicina, } \\
\text { sulforofano, } \\
\text { indole-3-carbinol }\end{array}$ & Vegetais crucíferosb & Pulmão \\
\hline Terpenos & $\begin{array}{l}\text { Monoterpenos, } \\
\text { sesquiterpenos }\end{array}$ & $\begin{array}{l}\text { Vegetais e frutos } \\
\text { (ex: citrinos) }\end{array}$ & \\
\hline
\end{tabular}

a - Exemplos de vegetais allium: alho, cebola, cebolinho...

b - Exemplos de vegetais crucíferos: brócolos, couve-flor, couve, agrião...

Tal como se apurou na leitura dos estudos que relacionam a ingestão de frutas e vegetais com a incidência de cancro, também aqueles que analisam o impacto do consumo de gordura no risco de desenvolvimento de doenças oncológicas são frequentemente inconclusivos. A interdependência que se verifica entre o consumo diário de gordura e outros fatores associados ao estilo de vida dificulta o isolamento deste primeiro parâmetro nos estudos epidemiológicos. Ainda assim, a maioria das publicações científicas relativas a esta área de estudos indicia a existência de uma associação positiva entre a ingestão de gordura e a incidência de cancro (Greenwald, Clifford \& Milner, 2001). Existem evidências de que a associação entre o consumo regular de carnes vermelhas e elevadas incidências de certos tipos de cancro - principalmente, para o caso do cancro colorretal, mas também para os cancros do estômago, pâncreas, bexiga, endométrio e ovário (Vecchia, 2004) - esteja relacionada com o elevado 
teor em gordura neste tipode produtos alimentares, embora não seja colocada de parte a hipótese de esta correlação se ficar a dever a outros elementos presentes na carne vermelha, como o heme ou as aminas cíclicas aromáticas, que se formam durante a fritura das carnes ou quando estas são grelhadas (Greenwald, Clifford \& Milner, 2001).

Mais do que a quantidade total de gorduras ingeridas, é o tipo de gordura consumida que mais pesa na determinação do risco de desenvolvimento de patologia oncológica. Se, por um lado, alimentos ricos em ácidos monoinsaturados (como o ácido oleico, abundante no azeite) ou em ácidos gordos $\omega$-3 (presentes em peixes gordos) demonstram ter um papel protetor contra cancros do trato digestivo superior, do cólon e reto e da mama (Vecchia 2004), alimentos com teor elevado em ácidos gordos $\omega-6$ (como o ácido linoleico, rico em óleos de sementes vegetais), por seu turno, parecem ser responsáveis por um aumento no risco de cancro da mama, próstata e cólon (Greenwald, Clifford \& Milner, 2001).

Finalmente, não deverá menosprezar-se o facto de o consumo excessivo de gorduras estar associado à obesidade, podendo ser um dos fatores-chave na promoção da oncogénese, particularmente em cancros que se relacionam com o excesso de peso, como é o cancro da mama em mulheres pós-menopáusicas (Rodrigues, 1993).

O papel dos hidratos de carbono na carcinogénese prende-se, fundamentalmente, com a ativação dos processos oncogénicos associados à insulina. Não obstante o facto de nem todos os estudos que incidem sobre este tema concreto acolherem unanimidade no seio da comunidade científica, pensa-se que alimentos com um elevado índice glicémico poderão favorecer o aumento do risco de cancro, nomeadamente do cancro da mama e do pâncreas, com especial incidência em grupos de alto risco - obesos e sedentários (McCullough \& Giovannucci, 2004).

O consumo excessivo de bebidas alcoólicas é outro fator envolvido na promoção da oncogénese, sobretudo quando associado a outros fatores de risco, elevando a incidência de cancro orofaríngeo, esofágico, colorretal, hepático, da laringe, da mama e do pulmão (Greenwald, Clifford \& Milner, 2001). Tal como se pode inferir da leitura do gráfico 2, esta relação entre o etanol e o risco de cancro é particularmente dose-dependente (Pelucchi, Tramacere, Boffetta, Negri, \& Vecchia, 2011). Vários estudos indicam ainda que a combinação do consumo etílico com o consumo tabágico tem um efeito potenciador no risco de cancro, particularmente do trato aerodigestivo (Greenwald, Clifford \& Milner, 2001).

O abuso de alimentos com elevado teor salino ou preservados em sal está particularmente relacionado com elevadas taxas de incidência de cancro do estômago. Sendo este tipo de conservação tradicional em culturas asiáticas, como ajaponesa, não é de estranhar que, em países como o Japão, a incidência de cancro gástrico seja especialmente alta (Péres-López, Chedraui, Haya \& Cuandros, 2009).

Ainda assim, a introdução de aparelhos de refrigeração neste país contribuiu para a diminuição do número de novos casos desta doença oncológica (gráfico 3); de entre outras vantagens, tal inovação permitiu a diminuição do recurso à salga de alimentos. Além de reduzir a necessidade de se recorrer a outros meios de preservação alimentar eventualmente carcinogénicos - nomeadamente a salga (Correa, Piazuelo \& Camargo, 2004) -, a refrigeração possibilita que se consumam alimentos perecíveis ainda frescos ou durante todo o ano, incluindo frutas e legumes sazonais, permitindo, adicionalmente, que se reduza o grau de contaminação microbiana e fúngica dos alimentos. A investigação científica demonstrou ainda que as vantagens referidas conferem ao processo de refrigeração uma função coadjuvante na redução do risco de vários tipos de cancro - da boca e faringe, laringe, nasofaringe, esófago, pulmão, estômago, pâncreas, fígado, cólon e reto (Péres-López, Chedraui, Haya \& Cuandros, 2009).

Finalmente, e em jeito de síntese, apresenta-se a tabela 5, que sumariza as recomendações dietéticas elaboradas pela American Cancer Society (ACS) para a prevenção de diferentes tipos de cancro, categorizadas em vários níveis de evidência científica por um subcomité desta associação (Byers, Nestle, McTiernan, Doyle, Currie-Williams, Gansler, et al., 2002). 


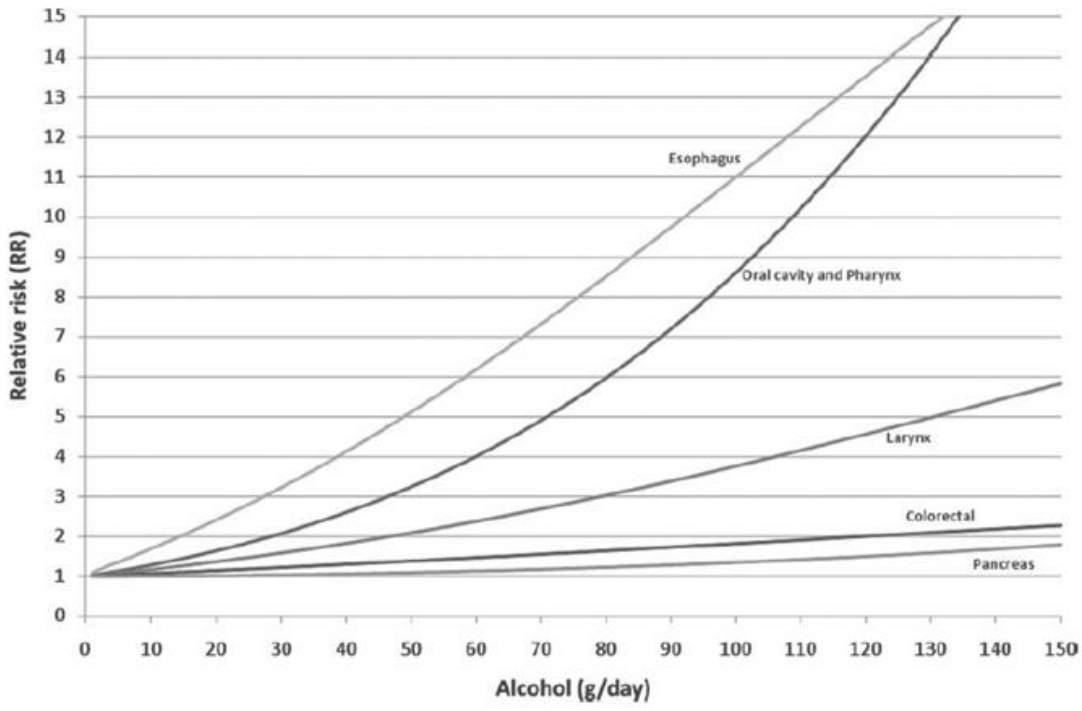

Figura 2. "Risco de desenvolvimento de determinados tipos de cancros (seleção), em relação à dose diária de álcool ingerido" [adaptado de (Pelucchi, Tramacere, Boffetta, Negri, \& Vecchia, 2011)].

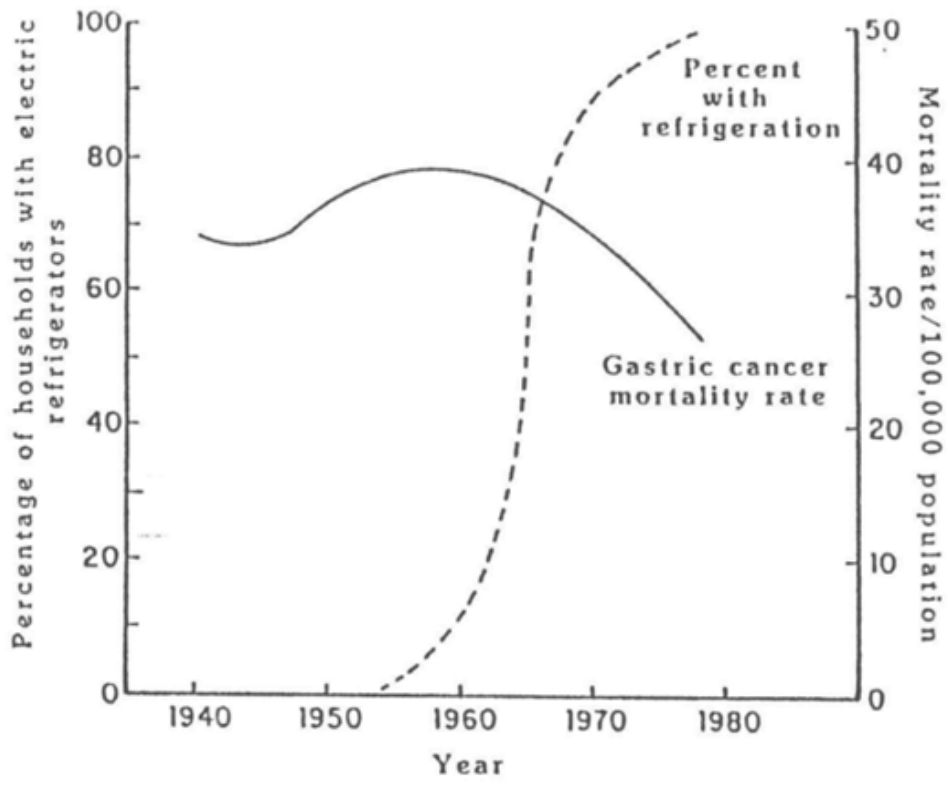

Figura 3. "Relação entre as taxas de mortalidade por cancro gástrico e a disponibilidade de aparelhos de refrigeração, ao longo do tempo, no Japão" [adaptado de (Howson, Hiyama \& Wynder, 1986)]

Tabela 5. Nível de evidência de algumas recomendações da ACS para a prevenção de diferentes tipos de cancro (benefício vs. malefício) [adaptado de (Byers, Nestle, McTiernan, Doyle, Currie-Williams, Gansler, et al., 2002)]

\begin{tabular}{ccccccccccc}
\hline $\begin{array}{c}\text { Localizações } \\
\text { tumorais }\end{array}$ & Colorretal & Mama & Próstata & Pulmão & $\begin{array}{c}\text { Boca/ } \\
\text { Esófago }\end{array}$ & Estômago & Pâncreas & Bexiga & Endométrio \\
\hline $\begin{array}{c}>\text { consumo de } \\
\text { fruta e } \\
\text { vegetais }\end{array}$ & A2 & A3 & A3 & A2 & A2 & A2 & A3 & A3 & A3 \\
\hline$<$ consumo de & A2 & B & A3 & B & B & C & A3 & C & B \\
\hline
\end{tabular}




\begin{tabular}{cccccccccc}
\hline $\begin{array}{c}\text { carnes } \\
\text { vermelhas } \\
>\begin{array}{c}\text { atividade } \\
\text { física }\end{array}\end{array}$ & A1 & A1 & B & B & B & B & B & B & A2 \\
\hline $\begin{array}{c}\text { Evitar o } \\
\text { excesso } \\
\text { de peso }\end{array}$ & A1 & A1 & C & B & A2 & B & A3 & C & A1 \\
\hline $\begin{array}{c}\text { consumo de } \\
\text { álcool }\end{array}$ & A3 & A2 & C & B & A1 & C & A3 & C & B \\
\hline $\begin{array}{c}>\text { consumo de } \\
\text { produtos de } \\
\text { soja }\end{array}$ & B & B & B & B & B & B & B & B & B \\
\hline $\begin{array}{c}\text { Suplementos } \\
\text { de B-caroteno }\end{array}$ & B & B & C & D & B & B & B & B & B \\
\hline $\begin{array}{c}\text { Suplementos } \\
\text { de vit. E }\end{array}$ & B & B & A3 & C & B & B & B & B & B \\
\hline $\begin{array}{c}\text { Suplementos } \\
\text { de vit. C }\end{array}$ & B & B & B & B & B & B & B & B & B \\
\hline $\begin{array}{c}\text { Suplementos } \\
\text { de folato }\end{array}$ & A3 & A3 & B & B & B & B & B & B & B \\
\hline $\begin{array}{c}\text { Suplementos } \\
\text { de selénio }\end{array}$ & A3 & B & A3 & A3 & B & B & B & B & B \\
\hline
\end{tabular}

Legenda:

A1 - Evidência convincente de benefício

A2 - Benefício provável

A3 - Benefício possível

$B$ - Evidência insuficiente para que se conclua se há benefício ou malefício

$C$ - Evidência de que não há benefício

$D$ - Evidência de malefício

\section{Dieta Mediterrânica e Cancro}

Face às noções expostas até aqui, facilmente se reconhecerá a mais-valia da Dieta Mediterrânica na prevenção do cancro. Vegetais, fruta, peixe e azeite são os principais componentes deste regime alimentar que contribuem para a diminuição do risco de desenvolvimento de doenças oncológicas (Simopoulos, 2001). Numa publicação de Tichopoulou et al. (2000), estima-se, aliás, que uma alteração da dieta dos países ocidentais mais desenvolvidos para um regime alimentar que se aproximasse mais da Dieta Mediterrânica tradicional poderia resultar na prevenção de cerca de $25 \%$ de novos casos de cancro colorretal, $\sim 15 \%$ de cancro da mama e $\sim 10 \%$ de cancros da próstata, do pâncreas e do endométrio.

No âmbito dos estudos epidemiológicos que analisam a correlação entre o seguimento das linhas gerais da Dieta Mediterrânica e a incidência de várias localizações tumorais, muito há ainda por explorar. Ainda assim, o número de publicações que incidem sobre este tema tem vindo a aumentar nos últimos anos, particularmente graças ao interesse acrescido que este regime dietético tem suscitado na comunidade científica, em virtude do seu comprovado papel na prevenção de muitas outras doenças crónicas.

Numa população de 25.623 participantes do segmento grego da coorte EPIC, avaliou-se o impacto da Dieta Mediterrânica na incidência de doenças oncológicas em geral, ao longo de um período médio de 7,9 anos (Benetou, Trichopoulou, Orfanos, Naska, Lagiou, Boffetta, et al., 2008). Observou-se que a adesão a este regime estaria implicada na redução da incidência de cancro, estando um aumento de 2 pontos na escala de Dieta Mediterrânica associado a um risco relativo de 0,88. Todavia, os autores apontam para o facto de, não obstante a Dieta Mediterrânica revelar uma associação inversa forte e significativa com o risco de cancro, essa relação dever ser considerada estatisticamente insignificante para os vários componentes da dieta, quando encarados individualmente. 
Relativamente à taxa de mortalidade por doenças oncológicas, Mitrou et al. (2007) incluíram, no seu estudo de 2007, 214.284 homens e 166.012 mulheres do NIH-AARP Diet and Health Study, realizado nos EUA, verificando que uma elevada adesão a uma Dieta Mediterrânica estaria associada à sua diminuição em $12 \%$, dados que vêm ao encontro de um estudo anterior levado a cabo na Grécia (Trichopoulou, Costacou, Bamia, \& Trichopoulos, 2003), onde, contudo, este decréscimo se havia revelado mais significativo - na ordem dos $24 \%$. Um grupo de investigadores suecos desenvolveu, igualmente, um estudo semelhante (Lagiou, Trichopoulos, Sandin, Lagiou, Mucci, Wolk, et al., 2006), desta feita numa população composta exclusivamente por mulheres - um total de 42.237, com idades entre os 30 e os 49 anos. Concluíram que, apesar de não se verificar qualquer relação entre a mortalidade e a Dieta Mediterrânica em participantes com menos de 40 anos, foi estabelecida, para além desta idade, uma influência protetora deste regime alimentar no risco de morte por cancro, de tal forma que um aumento de 2 pontos na escala de Dieta Mediterrânica se correlacionaria com uma diminuição de 16\% na taxa de mortalidade por doença oncológica.

Bosetti et al. (2003) são responsáveis por um artigo de revisão no qual foram analisados três estudos que colocavam a hipótese de a Dieta Mediterrânica ter um efeito protetor no desenvolvimento de diferentes tipos de cancro da via aerodigestiva superior. Em todos os casos, numa escala de Dieta Mediterrânica, uma adesão igual ou superior a 6 , em relação a uma inferior a 3, revelou diminuir o risco relativo de doença neoplásica - os valores de risco relativo situaram-se em 0,40 para o cancro oral e faríngeo, em 0,26 para o esofágico e em 0,23 para o laríngeo. Um estudo mais recente (Filomeno, Bosetti, Garavello, Levi, Galeoe, Negri, et al., 2014) revelou mesmo que face a indivíduos que apenas incorporam no seu regime alimentar dois componentes de Dieta Mediterrânica, aqueles que adotam seis ou mais componentes apresentam um risco relativo de 0,20 para tumores da cavidadade oral ou da faringe. Também em 2016 foi publicado um estudo relativo a uma população italiana (Giraldi, Panic, Cadoni, Boccia \& Leoncini, 2016), que confirmou o carácter protetor da Dieta Mediterrânica no desenvolvimento de tumores orofaríngeos e da laringe, estando uma maior adesão a este regime alimentar associado a um risco relativo de 0,61 para neoplasias da orofaringe e de 0,64 para tumores da laringe. Já em 2017, outro estudo numa população italiana (Turati, Bravi, Polesel, Bosetti, Negri, et al., 2017), constatou que $22 \%$ de neoplasias da nasofaringe da população estudada podiam ter sido evitados caso todos os elementos cumprissem mais de 6 pontos na escala de Dieta Mediterrânica.

Entre 1995 e 2006, Dixon et al. (2013) seguiram um total de 494,968 participantes num estudo que procurou averiguar se uma maior adesão à Dieta Mediterrânica teria alguma relação com a incidência de neoplasias gástricas e esofágicas. Concluíram que a Dieta Mediterrânica apenas se associaria significativamente a uma menor incidência de carcinomas espinocelulares do esófago, mas não de adenocarcinomas do estômago ou do esófago. Contrariando estes resultados, duas publicações relativas a populações italianas (Praud, Bertuccio, Bosetti, Turati, Ferraroni, et al., 2014; Stojanovic, Giraldi, Arzani, Pastorino, Biondi, et al., 2017) verificaram não só que indivíduos que seguiam uma dieta mais próxima dos padrões mediterrânicos teriam um risco significativamente menor de desenvolver cancro gástrico, mas também que mais de $20 \%$ destas neoplasias poderiam ser evitadas se todos os indivíduos seguissem uma dieta com uma pontuação mais elevada na escala de Dieta Mediterrânica (Praud, Bertuccio, Bosetti, Turati, Ferraroni, et al., 2014). Os elementos deste padrão alimentar que mais contribuirão para conferir proteção contra cancro gástrico serão o consumo elevado de vegetais, legumes e peixe, conjugado com consumo menor de carne e bebidas alcoólicas (Stojanovic, Giraldi, Arzani, Pastorino, Biondi, et al., 2017).

Para avaliar o impacto de diferentes dietas no desenvolvimento de adenoma colorretal, Dixon et al. (2007) quantificaram a incidência desta neoplasia, através de sigmoidoscopia, em indivíduos do PLCO (Prostate, Lung, Colorectal, and Ovarian Cancer Screening Trial), e confrontaram os dados recolhidos com a adesão à dieta DASH ou à Dieta Mediterrânica de cada indivíduo. Concluiu-se que o seguimento de cada uma delas acarretava uma diminuição do risco de desenvolver adenoma colorretal, tendo-se este último regime alimentar revelado mais fácil de adotar do que a dieta DASH. Este estudo mostrou que homens com uma adesão igual ou superior a 6, numa escala de Dieta Mediterrânica, apresentavam um risco $21 \%$ menor de adenoma colorretal e $29 \%$ um risco mais reduzido de adenoma avançado, em comparação com aqueles que apenas pontuaram 2 ou menos na mesma escala. Outras publicações mais recentes vieram corroborar estes dados: Kontou et al. (2012) determinou que a cada aumento de 1 ponto na escala de Dieta Mediterrânica se associaria a um risco relativo de desenvolvimento de carcinoma colorretal de 0,88; Bamia et al. (2013) estimou uma redução de risco de carcinoma colorretal de $11 \%$ em indivíduos com pontuações de 6-9 numa escala de Dieta Mediterrânica quando comparado com aqueles com apenas 0-3 pontos; 
em 2014, Grosso et al. (2014) publicou um estudo de caso-controlo com 338 pacientes com carcinoma colorretal e 676 indivíduos saudáveis, onde revela que o risco relativo de desenvolvimento de carcinoma colorretal será de 0,46 para indivíduos com adesão mais elevada a um padrão de dieta mediterrânica em comparação com aqueles com adesão menor; outro estudo semelhante publicado em 2016 (Rosato, Guercio, Bosetti, Negri, Serraino, et al., 2016) com 3745 casos de carcinoma colorretal e 6804 controlos determinou um risco relativo de 0,52 para estas mesmas classes.

A relação da Dieta Mediterrânica com tumores do fígado e vias biliares também já foi estudada; Turati et al. (2014) calculou um risco relativo de desenvolvimento de hepatocarcinoma de 0,66 e 0,51 em indivíduos seguindo regimes alimentares com 4 ou 5 pontos na escala de Dieta Mediterrânica, em comparação com aqueles que apenas obtiveram 0-3 pontos; Larsson et al. (2017) publicou um estudo prospetivo numa população sueca em que constatou uma associação inversa entre o grau de adesão à dieta Mediterrânica e o risco de desenvolvimento de colangiocarcinoma extra-hepático e carcinoma da vesícula biliar, o mesmo não se verificando para colangiocarcinomas intra-hepáticos.

Reunindo dados de dois estudos de caso-controlo Bosetti et al. (2013) concluiu que níveis mas elevados de adesão à Dieta Mediterrânica (comparando pontuações numa escala de Dieta Mediterrânica $\geq 6$ e <3) se associam significativamente a um menor risco de desenvolvimento de cancro pancreático $(R R=0,51-0,56)$, verificando-se um benefício sinérgico entre os vários componentes desta dieta. Numa publicação referente a uma população italiana, publicado em 2015 (Rosato, Polesel, Bosetti, Serraino, Negri, et al., 2015), concluiu-se ainda que 11,9\% dos tumores pancreáticos eram atribuíveis a baixos níveis de adesão à Dieta Mediterrânica, pelo que poderiam ser evitados através de simples alterações no estilo de vida dessa população.

Sugerindo uma dieta com muitos componentes em comum com a Dieta Mediterrânica, Pierce et al. (2007) avaliaram se um padrão alimentar rico em vegetais, fruta e fibra e com pouca gordura total influenciaria o prognóstico em doentes com cancro da mama. Verificou-se, contudo, que, ao longo de um follow-up de 7,3 anos, não se verificou qualquer redução do número de recorrências de cancro nem alteração na mortalidade, entre os sobreviventes de cancro da mama num estadio inicial. Ainda assim, mais recentemente, em 2014, Mourouti et al. (2014) publicou um estudo em que se verificou que o aumento de um ponto na escala de Dieta Mediterrânica se associava a uma diminuição de risco de cancro da mama de $9 \%$, sendo o consumo de cereais integrais, vegetais, fruta e álcool os fatores protetores mais importantes.

Dois estudos de caso-controlo realizados em Itália (Bosetti, Negri, Franceschi, Pelucchi, Talamini, Montella, et al., 2001) e na Grécia (Tzonou, Hsieh, Polychronopoulou, Trichopoulos, Kaprinis, Toupadaki, et al. 1993) propuseram-se averiguar de que forma determinados padrões alimentares se correlacionam com a incidência do cancro do ovário. Resultou que, em termos nutricionais, uma redução do risco relativo só se verificou para as gorduras monoinsaturadas $(R R=0,80)$ e para as fibras $(R R=0,73)$, não se tendo revelado estatisticamente relevantes as associações estabelecidas para a energia total, proteínas, gorduras saturadas, gorduras polinsaturadas, colesterol, hidratos de carbono, sacarose, vitaminas A e C, riboflavina e cálcio. Apurou-se, adicionalmente, que o consumo de carnes vermelhas aumentaria significativamente o risco de cancro do ovário $(R R=1,53)$, ao mesmo tempo que o consumo de peixe, vegetais crus, vegetais cozinhados e leguminosas contribuiriam para a prevenção desta doença oncológica ( $R R=0,51 ; 0,47 ; 0,65 ; 0,77$, respetivamente). Na publicação grega sugere-se que as associações encontradas poderiam explicar a incidência relativamente baixa de cancro do ovário na Grécia e em outros países mediterrânicos, além de fornecerem uma explicação plausível para a tendência de aumento da incidência desta patologia nestes mesmos países, durante as últimas décadas.

Em 2012 Ferrís-Tortajada et al. (2012) realizaram uma revisão de artigos relacionados com as implicações de fatores de risco dietéticos na etiopatogenia do carcinoma prostático, dando particular relevo àqueles que caracterizam a Dieta Mediterrânica tradicional. Considerando que os fatores de risco dietético estão associados a $10-12 \%$ da mortalidade por cancro da próstata, os principais atributos da Dieta Mediterrânica que foram considerados como protetores contra esta patologia neoplásica foram (i) a elevada ingestão diária de produtos vegetais (cereais, legumes, fruta fresca, frutos secos, tubérculos, vegetais); (ii) a utilização do azeite como principal fonte de gordura; (iii) o baixo consumo de gordura saturada de origem animal; (iv) a ingestão de carne vermelha processada, leite e produtos lácteos em quantidades reduzidas; (v) o consumo regular de peixes pequenos e (vi) o acompanhamento das refeições principais com pequenas porções de vinho. O papel nuclear neste efeito benéfico da Dieta 
Mediterrânica foi atribuído aos seus compostos fitoativos (licopeno, lupeol, quercetina, genisteína, carnosol, resveratrol, catecinas, vitaminas, entre outros), com propriedades antioxidantes e anti-inflamatórias. Este trabalho de revisão veio confirmar os resultados de um outro, realizado anteriormente por Itsiopoulos et al. (2009), que já tinham posto em evidência a importância dos fatores ambientais modificáveis no desenvolvimento do carcinoma da próstata, tal como indicavam estudos levados a cabo em comunidades migrantes. Nesta publicação, dá-se destaque à baixa incidência deste tipo de neoplasia na Grécia e em comunidades gregas na Austrália, em comparação com as taxas verificadas em naturais deste último país e do restante "mundo ocidental". Para explicar estes dados, dá-se como explicação o facto de a Dieta Mediterrânica tradicional, rica em nutrientes bioativos, conferir proteção aos gregos emigrantes que a continuam a seguir, mesmo no país de acolhimento. Adicionalmente, sugere-se que este padrão alimentar poderá ser uma alternativa aceitável para a prevenção desta doença oncológica.

Não obstante a identificação dos hábitos tabágicos e da exposição ocupacional ao fumo como as principais causas de cancro do pulmão, pesquisas epidemiológicas recentes têm vindo a acumular evidência de que os hábitos dietéticos também poderão desempenhar um papel importante na etiologia desta patologia oncológica - particularmente, o consumo de frutas e vegetais como fatores protetores e a ingestão de álcool, carnes salgadas, gordura e colesterol como elementos associados a um aumento do risco de oncogénese. É, justamente, esta a ideia que é defendida por um grupo de investigação italiano, numa publicação em que se avalia a relação entre os componentes da Dieta Mediterrânica e o cancro do pulmão (Fortes, Forastiere, Farchi, Mallone, Trequattrinni, Anatra, et al., 2003). Os resultados deste estudo sugerem que o consumo de cenoura, tomate, carnes brancas e, principalmente, de sálvia e de azeite estão associados a uma diminuição do risco de cancro do pulmão, após um cuidadoso controlo dos hábitos tabágicos. Em 2016, Hodge et al. (2016) publicou um estudo prospetivo que confirma estes resultados: o risco relativo de cancro do pulmão para indivíduos que seguem dietas com 7 a 9 pontos na escala de Dieta Mediterrânica em comparação com aqueles com menos de 3 pontos é de 0,64 glabalmente e de 0,38 para fumadores.

\section{Dieta Mediterrânica em Portugal}

A dieta tradicional portuguesa não é uma réplica da tradicional Dieta Mediterrânica. Tal como foi sublinhado, o padrão alimentar da bacia do Mediterrâneo apresenta diferentes variações nas diversas regiões que a integram, e Portugal não constitui exceção. Com um clima temperado pela proximidade atlântica, Portugal, de acordo com o nosso mais prestigiado geógrafo, Orlando Ribeiro, só é verdadeiramente "mediterrânico" do extremo Sul até à região da Arrábida (Durão, Oliveira \& Almeida, 2008; Ribeiro, 1998). Nas regiões do Norte, a humidade e pluviosidade, as temperaturas, a luminosidade e os ventos representam um padrão bem diferente daquele que é o modelo climático típico das regiões do Mediterrâneo, influenciador da chamada "dieta atlântica da Europa do Sul" (SEAD) (Oliveira, Lopes, \& Rodríguez-Artalejo, 2010). Ainda assim, com um modo de vida e uma cultura tipicamente mediterrânica, trazidos, essencialmente, pela romanização, e fortalecidos durante o período de presença árabe na Península Ibérica, os nossos antepassados desde cedo procuraram moldar a terra e a vegetação locais, aproximando as suas características das que se podiam observar na bacia do Mediterrâneo - a oliveira, que prefere o calor e os verões secos, já se cultiva, há muito, do Algarve ao Minho e em altitudes que não Ihe são características; o cultivo da vinha, típica do Sul da Península, expandiu-se a todo o território nacional, pensa-se que já no tempo dos romanos (Durão, Oliveira \& Almeida, 2008). Com uma elevada dependência dos "produtos da terra" (repare-se que, até à II Guerra Mundial, o setor primário constituía cerca de $80 \%$ da atividade económica portuguesa) e com uma significativa produção e uso de azeite, é fundamentalmente no avultado consumo de peixe e de marisco favorecido pelos estreitos vínculos que, desde sempre, se estabeleceram entre os portugueses e o Atlântico - que a dieta tradicional de Portugal imprime a sua diferença face àquela que foi descrita, inicialmente, por Allbaugh e Keys em Creta, e que também se pode encontrar no resto da Grécia, no Sul de Itália, no Chipre, por exemplo. Trata-se de uma marca diferenciadora que não deixa de conferir algumas vantagens à dieta portuguesa, enriquecendo-a em ácidos gordos $\omega-3$, por exemplo, cujo contributo na redução da incidência de arritmias, HTA, morte súbita cardíaca, algumas doenças oncológicas e patologias do foro neurológico e psiquiátrico, entre outras, se revela deveras importante.

No entanto, nas últimas décadas, assistiu-se a um fenómeno de transição epidemiológica em Portugal, caracterizado pela transformação de uma economia subdesenvolvida, mas ligada a hábitos saudáveis próximos dos padrões mediterrânicos tradicionais, numa economia de mercado desenvolvida. Em termos alimentares, esta transição 
provocou um afastamento da população portuguesa de um conjunto significativo de produtos alimentares que era produzido no país. A diminuição do consumo de fruta, vegetais, leguminosas e azeite, acompanhada de um consumo exagerado de carnes vermelhas e de outras gorduras saturadas, propiciou que se instalasse um padrão patológico em Portugal semelhante ao que se verificava nos países que já seguiam uma "dieta ocidentalizada". Observou- -se, verdadeiramente, um fenómeno de transição de risco, proporcionada, não só por esta mudança alimentar, mas também pela adoção de um estilo de vida mais sedentário, associado à obesidade, e de outras práticas "menos saudáveis", como o consumo de álcool e o tabagismo.

Torna-se, deste modo, evidente que o modelo de alimentação tradicional português tem que ser reabilitado e reavivado. Trata-se de uma missão importante, que não deve ficar apenas a cargo dos responsáveis pelos Cuidados de Saúde Primários, mas também por especialistas de outras áreas, científicas e económicas, para que se incentive a retoma dos modelos clássicos de alimentação. A DGS publicou em 2013 um conjunto de dez recomendações para que os portugueses repensem as suas escolhas alimentares e adotem um padrão alimentar que é, ao mesmo tempo, simples, económico e saudável. Estes conselhos incluem fazer da água a principal bebida do dia, iniciar as refeições principais com uma sopa de hortícolas, incluir leite e laticínios nas pequenas refeições do dia, escolher pão de qualidade, investir nas capacidades culinárias, fazer compras de proximidade, levar fruta ao sair de casa, experimentar novos sabores e atividades, controlar o peso, estimular a atividade física e desconfiar de soluções milagrosas para perder peso sem esforço (Direção-Geral da Saúde, 2011). Resumindo, é fundamental que se revalorize aquilo que é produzido localmente, os produtos que são característico da natureza "mediterrânica" de Portugal, bem como o que é substancialmente mais saudável e que pode, inclusivamente, revelar-se mais económico.

\section{Referências}

Albert, C. M., Hennekens, C. H., O’Donnell, C. J., Ajani, U. A., Carey, V. J., Willett, W. C., et al. (1998). Fish Consumption and Risk of Sudden Cardiac Death. The Journal of the American Medical Associa tion. 23-28.

Allbaugh, L. G. (1953). Crete: a case study of an underdeveloped area Princeton. NJ: Princeton University Press.

Bamia, C., Lagiou, P., Buckland, G., Grioni, S., Agnoli, C., et al. (2013). Mediterranean diet and colorectal cancer risk: results from a European cohort. European Journal of Epidemiology. 317-328.

Benetou, V., Trichopoulou, A., Orfanos, P., Naska, A., Lagiou, P., Boffetta, P., et al. (2008). Conformity to traditional Mediterranean diet and cancer incidence: the Greek EPIC cohort. British Journal of Cancer. 191-195.

Blackburn, H. (2012). School of Public Health - University of Minesota. [Online]. [cited 2012 Dezembro 22]. Retrieved from: http://www.sph.umn.edu/epi/history/overview/.

Bosetti, C, Negri, E., Franceschi, S., Pelucchi, C., Talamini, R., Montella, M., et al. (2001). Diet and ovarian cancer risk: a case-control study in Italy. International Journal of Cancer. 911-915.

Bosetti, C, F Turati, A Dal Pont, M Ferraroni, J Polesel, et al. 2013. The role of Mediterranean diet on the risk of pancreatic cancer. British Journal of Cancer. 1360-1366.

Bosetti, C., Gallus, S., Trichopoulou, A., Talamini, R., Franceschi, S., Negri, E., et al. (2003). Influence of the Mediterranean diet on the risk of cancers of the upper aerodigestive tract. Cancer Epidemiology, Biomarkers \& Prevention. 1091-1094.

Byers, T., Nestle, M., McTiernan, A., Doyle, C., Currie-Williams, A., Gansler, T., et al. (2002). American Cancer Society Guidelines on Nutrition and Physical Activity for Cancer Prevention: Reducing the Risk of Cancer with Healthy Food Choices and Physical Activity. A Cancer Journal for Clinicians. 92-119.

Chahoud G., Aude, Y. W., \& Mehta, J. L. (2004). Dietary Recommendations in the Prevention and Treatment of Coronary Heart Disease: Do We Have the Ideal Diet Yet? The American Journal of Cardiology. 1260-1267.

Cordova, A. C., \& Sumpio, B. J. (2012). Perfecting the Plate: Adding Cardioprotective Compounds to the Diet. Journal of the American College of Surgeons. Janeiro: 97-114. 
Correa, P., Piazuelo, M. B., \& Camargo, M. C. (2004). The future of gastric cancer prevention. Gastric Cancer. 9-16.

Direção-Geral da Saúde [Online]. (2011). [cited 2017 Junho 12]. Retrieved from: http://www.dgs.pt/upload/memb ro.id/ficheiros/i008723.pdf .

Dixon, L., Subar, A., Peters, U., Weissfeld, J., Bresalier, R., Risch, A., et al. (2007). Adherence to the USDA Food Guide, DASH Eating Plan, and Mediterranean dietary pattern reduces risk of colorectal adenoma. The Journal of Nutrition. 2443-2450.

Durão, C., Oliveira, J., \& Almeida, M. (2008). Portugal e o Padrão Alimentar Mediterrânico. Alimentação Humana. 115-128.

Ferrari, R., \& Rapezzi, C. (2011). The Mediterranean diet: a cultural journey. The Lancet. 1730-1731.

Ferrís-Tortajada, J., Berbel-Tornero, O., García-Castell, J., Ortega-García, J., \& López-Andreu, J. (2012). Dietetic factors associated with prostate cancer: protective effects of Mediterranean diet. Actas Urologicas Españolas. 239245

Filomeno, M., Bosetti, C., Garavello, W., Levi, F., Galeoe, C., Negri, E., et al. (2014). The role of a Mediterranean diet on the risk of oral and pharyngeal cancer. British Journal of Cancer. 982-986.

Fortes, C., Forastiere, F., Farchi, S., Mallone, S., Trequattrinni, T., Anatra, F., et al. (2003). The Protective Effect of the Mediterranean Diet on Lung Cancer. Nutrition and Cancer. 30-37.

Fundación Dieta Mediterránea [Online]. (2012aํ). La pirámide de la Dieta Mediterránea se actualiza para adaptarse al estilo de vida actual. [cited 2012 Dezembro 23]. Retrieved from: http:// dietamediterranea.com/piramidedietamediterranea/.

Fundación Dieta Mediterránea [Online]. (2012b). [cited 2012 Dezembro 23]. Retrieved from: http://dietamediterranea.com/dietamed/piramide_PORTUGUES.pdf.

Fundación Dieta Mediterránea [Online]. (2012c). ¿Qué es la Dieta Mediterránea?. [cited 2012 Dezembro 23]. Retrieved from: http://dietamediterranea.com/dieta-mediterranea/que-es-la-dieta-mediterranea/.

Galli, C., \& Marangoni, F. (2006). N-3 fatty acids in the Mediterranean diet. Prostaglandins, Leukotrienes and Essential Fatty Acids. 129-133.

Garaulet, M., Pérez-Llamas, F., Rueda, C., Zamora, S. (1998). Trends in the Mediterranean Diet in Children From South-East Spain. Nutrition Research. 979-988.

Giraldi, L., Panic, N., Cadoni, G., Boccia, S., \& Leoncini, E. (2016). Association between Mediterranean diet and head and neck cancer: results of a large case-control study in Italy. European Journal of Cancer Prevention. [Epub ahead of print].

Graça, P. (2012). Sessão de abertura da conferência de encerramento. 13 de dezembro de 2012. Ciclo de Conferências: O futuro da alimentação - ambiente, saúde e economia.

Greenwald, P., Clifford, C., Milner, J. (2001). Diet and cancer prevention. European Journal of Cancer. 948-965.

Gross, M. D. (2005). Vitamin D and Calcium in the Prevention of Prostate and Colon Cancer: New Approaches for the Identification of Needs. Journal of Nutrition. 326-331.

Grosso, G., Biondi, A., Galvano, F., Misteretta, A., Marventano, S., et al. 2014. Factors associated with colorectal cancer in the context of the Mediterranean diet: a case-control study. Nutrition and Cancer. 558-565.

Hodge, A., Bassett, J., Shivappa, N., Hérbert, J., English, D., et al. (2016). Dietary Inflammatory index, Mediterranean diet score, and lung cancer: a prospective study. Cancer Causes and Control. 907-917.

Howson, C., Hiyama, T., \& Wynder, E. (1986). The decline of gastric cancer: epidemiology of na unplanned triumph. Epidemiologic Reviews. 1-27.

Huang, C. L, \& Sumpio, B. E. (2008). Olive Oil, the Mediterranean Diet, and Cardiovascular Health. Journal of the American College of Surgeons. 407-416. 
Itsiopoulos, C., Hodge, A., \& Kaimakamis, M. (2009). Can the Mediterranean diet prevent prostate cancer? Molecular Nutrition \& Food Research. 227-239.

Lagiou, P., Trichopoulos, D., Sandin, S., Lagiou, A., Mucci, L., Wolk, A., et al. (2006). Mediterranean dietary pattern and mortality among young women: a cohort study in Sweden. The British Journal of Nutrition. 384-392.

Larsson, S., Håkansson, N., Wolk, A. (2017). Healthy dietary patterns and incidence of biliary tract and gallbladder cancer ina a prospective study of women and men. European Journal of Cancer. 42-47.

Léger-Guist'hau, J. (2011). Intérêt du régime méditerranéen: extrapolation à la nutrition entérale au long cours. D’après la communication d’E. Fontaine. Nutrition clinique et métabolisme.

Li, W., Park, Y., Wu, J., Ren, J., Goldstein, A., et al. (2013). Index-based dietary patterns and risk of esophageal and gastric cancer in a large cohort study. Clinical Gastroenterology and Hepatology. 1130-1136.

Keys, A., Aravanis, C., Blackburn, H., Buzina, R., Djprdjevic, B., Dontas, A., et al. (1980). Seven Countries: A multivariate analysis of death and coronary heart disease. Cambridge, MA: Harvard University Press.

Keys, A., \& Keys, M. (1959). Eat Well and Stay Well. New York, NY: Doubleday.

Kirsh, V. A., Peters, U., Mayne, S. T., Subar, A. F., Chatterjee, N., Johnson, C. C., et al. (2007). Prospective Study of Fruit and Vegetable Intake and Risk of Prostate Cancer. Journal of the National Cancer Institute. 1200-1209.

Knoops, K. T., Groot, L. C., Kromhout, D., Perrin, A. E., Moreiras-Varela, O., Menotti, A., et al. (2004).

Mediterranean Diet, Lifestyle Factors, and 10-Year Mortality in Elderly European Men and Women. The HALE Project. The Journal of the American Medical Association. 1433-1439.

Kontogianni, M.D., Vidra, N., Farmaki, A. E., Koinaki, S., Belogianni, K., Sofrona, S., et al. (2008).

Adherence Rates to the Mediterranean Diet Are Low in a Representative Sample of Greek Children and Adolescents. The Journal of Nutrition. 1951-1956.

Kontou, N., Psaltopoulou, T., Soupos, N., Polychronopoulos, E., Xinopoulos, D., et al. (2012). Metabolic syndrome and colorectal cancer: The protective role of Mediterranean diet - a case-control study. Angiology. 390-396.

Machado, J. P. (1995). Dicionário Etimológico da Língua Portuguesa, II. 7th ed. Lisboa: Livros Horizonte.

McCullough, ML, EL Giovannucci. 2004. Diet and cancer prevention. Oncogene. 6349-6364.

Michels, K. B., Mohllajee, A. P., Roset-Bahmanyar, E., Beehler, G. P., Moysich, K. B. (2007). Diet and Breast Cancer. A Review of the Prospective Observational Studies. Cancer. 2712-2749.

Michels, K. B., Giovannucci, E., Joshipura, K. J., Rosner, B. A., Stampfer, M. J., Fuchs, C. S., et al. (2000).

Prospective study of fruit and vegetable consumption and incidence of colon and rectal cancers. Journal of the National Cancer Institute. 1740-1752.

Mitrou, P. N., Kipnis, V., Thiébaut, A. C., Reedy, J., Subar, A. F., Wirfält, E., et al. (2007). Mediterranean Dietary Pattern and Prediction of All-Cause Mortality in a US Population - Results From the NIH-AARP Diet and Health Study. Archives of Internal Medicine. 2461-2468.

Mourouti, N., Kontogianni, M., Papavagelis, C., Plytzanopoulou, P., Vassilakou, T., et al. (2014). Adherence to the Mediterranean diet is associated with lower likelihood of breast cancer: a case-control study. Nutrition and Cancer. 810-817.

Nestle, M. (1995). Mediterranean diets: historical and research overview. The American Journal of Clinical Nutrition. 1313S-1320S.

Neto, SdS. (1947). Fontes do latim vulgar Rio de Janeiro: Imprensa Nacional.

Oliveira, A., Lopes, C., Rodríguez-Artalejo, F. (2010). Adherence to the Southern European Atlantic Diet and occurrence of nonfatal acute myocardial infarction. American Journal of Clinical Nutrition. 211-217. 
Panagiotakos, D. B., Pitsavos, C., \& Stefanadis, C. (2006). Dietary patterns: A Mediterranean diet score and its relation to clinical and biological markers of cardiovascular disease risk. Nutrition, Metabolism \& Cardiovascular Diseases. 559-568.

Pelucchi, C., Tramacere, I, Boffetta, P., Negri, E., \& Vecchia, C. L. (2011). Alcohol Consumption and Cancer Risk. Nutrition and Cancer. 983-990.

Péres-López, F. R., Chedraui, P., Haya, J., \& Cuadros, J. L. (2009). Effects of the Mediterranean diet on longevity and age-related morbid conditions. Maturitas. 67-79.

Pierce, J., Natarajan, L., Caan, B., Parker, B., Greenberg, E., Flatt, S., et al. (2007). Influence of a diet very high in vegetables, fruit, and fiber and low in fat on prognosis following treatment for breast cancer: the Women's Healthy Eating and Living (WHEL) randomized trial. JAMA: Journal of the American Medical Association. 289-298.

Praud, D., Bertuccio, P., Bosetti, C., Turati, F., Ferraroni, M., et al. (2014). Adherence to the Mediterranean diet and gastric cancer risk in Italy. International Journal of Cancer. 2935-2941

Ribeiro, O. Portugal, (1998). O Mediterrâneo e o Atlântico. 7th ed. Lisboa: Livraria Sá da Costa Editora.

Rodrigues, V. J. L. (1993). Epidemiologia Geográfica de Cancro. Aplicação de Estimativa Bayesiana Empírica à Análise da Distribuição Geográfica da Mortalidade por Tumores Malignos em Portugal. Dissertação de Doutoramento Apresentada à Faculdade de Medicina da Universidade de Coimbra.

Rosato, V., Polesel, J., Bosetti, C., Serraino, D., Negri, E., et al. (2015). Population attributable risk for pancreatic cancer in Northern Italy. Pancreas. 216-220.

Rosato, V., Guercio, V., Bosetti, C., Negri, E., Serraino, D., et al. (2016). Mediterranean diet and colorectal cancer risk: a pooled analysis of three Italian case-control studies. British Journal of Cancer. 862-865.

Simopoulos, A. P. (2001). The Mediterranean Diets: What Is So Special about the Diet of Greece? The Scientific Evidence. The Journal of Nutrition. 3065S-3073S.

Slow Food [Online]. [cited 2012 Dezembro 28]. Retrieved from: http://slowfood.com/.Stojanovic, J, L Giraldi, D Arzani, R Pastorino, A Biondi, et al. 2017. Adherence to the Mediterranean diet and risk of gastric cancer: results of a case-control study in Italy. European Journal of Cancer Prevention. [Epub ahead of print].

Trichopoulou, A., Kouris-Blazos, A., Wahlqvist, M. L., Gnardellis, C., Lagiou, P., Polychronopoulos, E., et al. (1995). Diet and overall survival in elderly people. BMJ. 1457-1460.

Trichopoulou, A., Lagiou, P., Kuper, H., Trichopoulos, D. (2000). Cancer and Mediterranean Dietary Traditions. Cancer Epidemiology, Biomarkers \& Prevention. 869-873.

Trichopoulou, A., Costacou, T., Bamia, C., \& Trichopoulos, D. (2003). Adherence to a Mediterranean Diet and Survival in a Greek Population. The New England Journal of Medicine. 2599-2608.

Turati, F., Trichopoulos, D., Polesel, J., Bravi, F., Rossi, M., et al. (2014). Mediterranean diet and hepatocelular carcinoma. Journal of Hepatology. 606-611.

Turati, F., Bravi, F., Polesel, J., Bosetti, C., Negri, E., et al. (2017). Adherence to the Mediterranean diet and nasopharyngeal cancer risk in Italy. Cancer Causes and Control. 89-95

Tyrovolas, S., \& Panagiotakos, D. B. (2010). The role of Mediterranean type of diet on the development of cancer and cardiovascular disease, in the elderly: A systematic review. Maturitas. 122-130.

Tzonou, A., Hsieh, C. C., Polychronopoulou, A., Trichopoulos, D., Kaprinis, G., Toupadaki, N., et al. (1993). Diet and ovarian cancer: A case-control study in Greece. International Journal of Cancer. 411-414.

UNESCO - United Nations Educational, Scientific and Cultural Organization [Online]. 2012. [cited 2012 Dezembro 23]. Retrieved from: http://www.unesco.org/culture/ich/ index. php?lg=en\&pg=00011\&RL=00394.

Vecchia, C. L. (2004). Mediterranean diet and cancer. Public Health Nutrition. 965-968.

Willett, W. C. (1999). Dietary Fat and Breast Cancer. Toxicological Sciences. 127-146. 
Willett, W. C., Sacks, F., Trichopoulou, A., Drescher, G., Ferro-Luzzi, A., Helsing, E., et al. (1995). Mediterranean diet piramid: a cultural model for healthy eating. The American Journal of Clinical Nutrition. 1402S-1406S.

\section{Sobre os Autores}

Rodrigo Queiroz de Athayde Pinheira Nemésio (MsC) é, no presente, Interno de Formação Específica de Cirurgia Geral no Centro Hospitalar e Universitário de Coimbra. Atualmente, as suas áreas de interesse são a carcinogénese alimentar, a patologia oncológica do sistema digestivo e a cirurgia gastro-intestinal. Concluiu o Mestrado Integrado em Medicina na Faculdade de Medicina da Universidade de Coimbra em 2013 com uma tese intitulada "Estilos Alimentares e a Saúde - O Caso Específico dos Países do Sul da Europa". Nasceu em Coimbra a 18 de fevereiro de 1989. 